\title{
Hydrogen Production by Photoreforming of Renewable Substrates
}

\author{
Ilenia Rossetti \\ Dipartimento di Chimica, Università degli Studi di Milano, INSTM Unit Milano-Università and CNR-ISTM, \\ v. C. Golgi 19, 20133 Milano, Italy \\ Correspondence should be addressed to Ilenia Rossetti, ilenia.rossetti@unimi.it
}

Received 23 September 2012; Accepted 11 October 2012

Academic Editors: C.-T. Hsieh, C. Perego, I. Poulios, and A. M. Seayad

Copyright ( $\odot 2012$ Ilenia Rossetti. This is an open access article distributed under the Creative Commons Attribution License, which permits unrestricted use, distribution, and reproduction in any medium, provided the original work is properly cited.

This paper focuses on the application of photocatalysis to hydrogen production from organic substrates. This process, usually called photoreforming, makes use of semiconductors to promote redox reactions, namely, the oxidation of organic molecules and the reduction of $\mathrm{H}^{+}$to $\mathrm{H}_{2}$. This may be an interesting and fully sustainable way to produce this interesting fuel, provided that materials efficiency becomes sufficient and solar light can be effectively harvested. After a first introduction to the key features of the photoreforming process, the attention will be directed to the needs for materials development correlated to the existing knowledge on reaction mechanisms. Examples are then given on the photoreforming of alcohols, the most studied topic, especially in the case of methanol and carbohydrates. Finally, some examples of more complex but more interesting substrates, such as waste solutions, are proposed.

\section{Introduction}

$\mathrm{H}_{2}$ production through water splitting (WS) is thermodynamically limited by the high Gibbs-free energy $(237 \mathrm{~kJ} / \mathrm{mol}$, $1.23 \mathrm{eV}$ ), representing a typical uphill reaction. Nevertheless, solar energy storage as $\mathrm{H}_{2}$ by photocatalysis is an intriguing topic, but very low efficiency is reported for direct photocatalytic WS [1-3]. In order to reduce protons and oxidize oxygen ions, a semiconductor should possess a band gap energy higher than the required energy for such reaction. Moreover, the energy levels of the valence and conduction bands should be compatible with those of the species to be reduced or oxidized. Indeed, the electron, promoted someway in the conduction band, should have much negative potential than the redox couple $\mathrm{H}^{+} / \mathrm{H}_{2}$, and the hole left in the valence band should possess higher positive potential than $\mathrm{O}_{2} / \mathrm{H}_{2} \mathrm{O}$ (Figure 1). The band gap energies of many common oxides and sulphides have been recently recalled in [1], together with their performance in direct WS.

Since the first report of WS on $\mathrm{TiO}_{2}$ [5], various photocatalysts were developed [1], but the efficiency for WS remains very low [6-8]. Sacrificial reagents, such as methanol or EDTA, can improve hydrogen productivity, but they are nonrenewable [9]. Compared to thermochemical processes, photocatalytic reforming (PR) is a valid approach to produce $\mathrm{H}_{2}$ under ambient conditions and using sunlight, the cheapest energy source available on earth. PR is also thermodynamically more feasible than WS [10]. After a pioneering study in 1980 [11], the attention was more recently focused mostly on the PR of methanol, the simplest molecule, and a few examples of PR of compounds really obtainable from biomass can be found, for example, ethanol, glycerol [1214], glucose, sucrose [14], starch and wood [11], and sewage sludge [15]. Glucose and cellulose were also processed with homogeneous catalytic processes [16]. Interestingly, biomass-derived substrates, such as alcohols or carbohydrates, may be used for hydrogen production particularly in the case of waste materials (sewage from food, wine, or paper industry) [17], simultaneously helping to clean wastes (without disposal costs) and to produce a highly valued fuel [18]. On the other hand, technology is mature for the conversion of lignocellulosic biomass, not competing with the food and feed chain, into elementary alcohols and carbohydrates.

PR offers a route to $\mathrm{H}_{2}$ that, unlikely thermal reforming or gasification, may be exploited under ambient conditions and, using sunlight, it is particularly attractive for areas of 


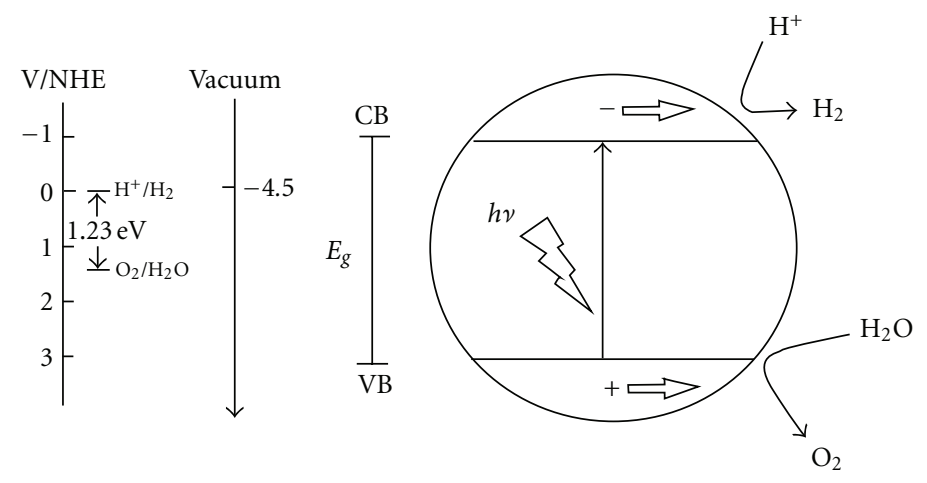

FIGURE 1: Basic mechanism of photocatalytic WS over semiconductors with proper band gap.

the world where high biomass supply coincides with high sunlight intensity. Furthermore, it is a relatively low tech method and therefore particularly useful for small production facilities and developing countries.

Various reviews have been published till now on WS (see e.g., $[1,19-25])$, whereas much more limited records can be found relative to PR. In this latter case the attention was predominantly focused on methanol as sacrificial agent and on the development of materials and mechanisms. In this work, besides recalling some of such points, the central topic will be the evaluation of $\mathrm{H}_{2}$ productivity of different materials and substrates to assess process feasibility and to critically compare various solutions.

\section{Materials and Mechanisms}

The mechanism of PR in aqueous medium is based on photon absorption by a semiconductor, which causes the photopromotion of an electron to the conduction band, with formation of positively charged holes in the valence band. The bandgap energy extension of the semiconductor has to fit the above mentioned requirements on coupling with the redox potential of the hydrogen reduction and oxygen oxidation half reactions. Therefore, it should be in general higher than $1.23 \mathrm{eV}$. However, if it overcomes $3 \mathrm{eV}$ solar light harvesting becomes minimal. Low efficiency is usually due to light scattering/reflection, poor absorption, and quick electron/hole recombination in the bulk or on the surface of catalyst particles [19] and fast back reaction of $\mathrm{O}_{2}$ and $\mathrm{H}_{2}$ during WS. The addition of small quantities of metals limit charge recombination [26], since excited electrons are captured by the metal and reduced protons. Metals should better have low overpotential for $\mathrm{H}_{2}$. Strong metal support interaction also improves the efficiency of the metal as electron scavenger helping in the decrease of electron/hole recombination in semiconductors photocatalysis $[17,27,28]$. However, the recombination rate increases at high metal loading because the distance between trapping sites in a particle decreases with the amount of metal, so that an optimum exists [29]. It is also worth mentioning the importance of the spill-over effect in the surface process for hydrogen production [17].

On the other hand, holes migrate to the surface where they oxidize the adsorbed organic molecules, so, another key factor to decrease the electron/hole recombination rate is the ability of the organic substrate as hole scavenger, in turn related with geometry and electronic structure upon adsorption [1-3].

The time scale of the different reaction steps is very different. The photoinduced generation of an electron-hole couple occurs in femtoseconds, their recombination in 10-100 ns. Reduction mediated by electrons needs a much longer time, in the order of ms, whereas the oxidative reaction carried out by holes takes $c a .100 \mathrm{~ns}$, a comparable time scale with respect to recombination. Therefore, electrons need to be preserved for longer time by trapping them into a metal where they can migrate, or by making holes react with a suitable hole scavenger [30, 31]. When a metal (with proper work function) is deposed on a semiconductor, excited electrons from the semiconductor migrate to the metal until the two Fermi levels are aligned. The Schottky barrier [10, 32] formed at the metal and semiconductor interface can serve as an efficient electron trap to prevent photogenerated electronhole recombination, greatly enhancing the efficiency of the photocatalytic reaction. The metal also serves as an active site for $\mathrm{H}_{2}$ production, in which the trapped photogenerated electrons are transferred to protons to produce $\mathrm{H}_{2}$.

Methanol and other organic compounds may act as sacrificial agents and hole scavengers in photocatalysis, being able to combine with photogenerated valence-band holes more efficiently than water. For instance, glucose is an efficient hole scavenger for titania [10,33-35]. Theoretical studies on glucose adsorption over titania showed distinct intragap states; this explains its hole trapping role in $\mathrm{TiO}_{2}$ [34]. Possible mechanisms for the whole PR process have been proposed, but this complex mechanism still needs validation. In aqueous solution other powerful oxidizing agents may be formed from surface adsorbed water, such as hydroxyl radicals and superoxide anions $\left(\mathrm{O}_{2}{ }^{-}\right)$which are able to oxidize and mineralize almost all organic pollutants yielding $\mathrm{CO}_{2}$. As a matter of fact, PR is a much less explored route for obtaining $\mathrm{H}_{2}$ from oxygenates, such as alcohols, or from biomass extracts and wastes [13,36,37].

The feasibility of PR of different biomass-derived compounds has been proved [38] with alcohols, organic acids, and different carbohydrates, such as ribose, arabinose, glucose, galactose, fructose, and mannose. In all cases, the amounts 
of excess $\mathrm{H}_{2}$ with respect to simple WS and $\mathrm{CO}_{2}$ produced are in accordance with the stoichiometry of the following reaction:

$$
\mathrm{C}_{x} \mathrm{H}_{y} \mathrm{O}_{z}+(2 x-z) \mathrm{H}_{2} \mathrm{O} \longrightarrow x \mathrm{CO}_{2}+(2 x-z+y / 2) \mathrm{H}_{2}
$$

The rate of $\mathrm{H}_{2}$ production depends strongly on the nature and concentration of the organic substrate and, to a lesser extent, on $\mathrm{pH}$ and temperature. For instance, $\mathrm{H}_{2}$ productivity under solar light irradiation as high as $c a$. $3.75 \mathrm{~mol} \mathrm{H}_{2} / \mathrm{h} \mathrm{kg}$ of photocatalyst $\left(0.5 \% \mathrm{Pt} / \mathrm{TiO}_{2}\right)$. The heat content of $\mathrm{H}_{2}$ produced was higher than that of the substrate, demonstrating efficient storage of solar energy.

Among the photocatalysts, $\mathrm{TiO}_{2}$ is a cheap, widely available and chemically stable, wide bandgap energy semiconductor, hence, the most studied material $[39,40]$. Its main properties and photocatalytic application issues have been extensively reviewed recently [41]. However, its main drawback is the scarce harvesting of sunlight, $\mathrm{TiO}_{2}$ absorbing in the UV region, which constitutes not more than $5 \%$ of the solar spectrum. The crystalline phase of $\mathrm{TiO}_{2}$ is also believed to be a pivotal factor for $\mathrm{H}_{2}$ production $[10,42,43]$. However, there is not univocal interpretation on the activity of the different crystal phases. Anatase is often considered the most active single phase photocatalyst, though its coupling with rutile may lead to the most interesting results [44]. Indeed, the photogenerated electrons in the anatase crystals may transfer to the conduction band of the rutile crystal and contribute to the reduction of $\mathrm{H}^{+}$. The valence bands of both phases have similar energy and thus contribute to the photooxidation of methanol in the same way. Furthermore, the anatase structure is usually more defective than the rutile one, but oxygen defects are alternatively believed as efficient electron traps, enhancing charge separation [45], or undesired recombination sites [46].

Other materials, such as $\mathrm{La}$ doped $\mathrm{NaTaO}_{3}$ [47], $\mathrm{Sr}_{2} \mathrm{Nb}_{2} \mathrm{O}_{7} \quad$ [48], $\quad \mathrm{Sr}_{2} \mathrm{Ta}_{2} \mathrm{O}_{7}$ [48], $\mathrm{La}_{2} \mathrm{Ti}_{2} \mathrm{O}_{7}$ [49], $\mathrm{K}_{2} \mathrm{La}_{2} \mathrm{Ti}_{3} \mathrm{O}_{10}$ [50] have been also proposed for WS, but they share with $\mathrm{TiO} 2$ the drawback of absorption only in the UV region, thus limiting solar light harvesting. Another very active photocatalyst is $\mathrm{NaTaO}_{3}$, with $\mathrm{NiO}$ as cocatalyst, which however keeps the limitation of absorption in the UV range only [51]. A recent review focused on various materials for photocatalytic applications, where some suggestions on photocatalyst properties are proposed [52].

The effect of crystal or particle size is not univocal, since on one hand quantum confinement of photogenerated charges, revealing for nanometric systems, should enhance activity. Furthermore, increased available surface sites concentration usually improves catalyst activity [53-55]. Nevertheless, surface recombination of electron and holes may prevail, thus limiting the overall activity of the sample [56]. Also porosity may be important since holes may migrate to the surface of micro- or mesopores to oxidize an organic substrate, provided that it is able to diffuse inside the pores. The complementary $\mathrm{H}^{+}$reduction reaction may occur on the external surface, where some metal nanoparticles may be present, drawing the photogenerated electrons. This physical separation of the reaction sites may help to avoid charge recombination, more likely if both species, electrons, and holes, should else migrate towards the external surface [57].

Besides offering a high catalytic activity [58], nanomaterials can provide enhanced performances thanks to a suppression of ohmic losses, usually occurring in bulk semiconductors $[59,60]$. In addition, the band gap energy may be in principle tuned with particle size, in order to increase light absorption in the solar spectrum [61]. However, size effects sometimes induce an upward/downward shift of the $\mathrm{CB} / \mathrm{VB}$ edges, complicating the prediction of the exact band positions [62].

Finally, morphology also showed important, especially when 1D nanostructures have been developed, such as nanotubes and nanowires [63-66]. The higher photocatalytic activity of such systems is usually attributed to the high surface area combined with the short diffusion path of the photoexcited species across the bulk to reach the surface, where the reactants are adsorbed [66]. The effect of structure and morphology of semiconductors active for WS has been also recently reviewed [67].

The role of metal ions or oxides as cocatalysts has been enunciated since long time. For instance, bare $\mathrm{TiO}_{2}$ was almost inactive for both WS and PR of alcohols, whereas $1.0 \mathrm{wt} \%$ loading of various noble metals, such as $\mathrm{Pt}, \mathrm{Pd}, \mathrm{Au}$, $\mathrm{Rh}, \mathrm{Ag}$, and $\mathrm{Ru}$, improved $\mathrm{H}_{2}$ evolution. The activity scale (better results with $\mathrm{Pd}$ and $\mathrm{Pt}$ ) was correlated with the workfunction of the metal. $\mathrm{TiO}_{2}$ has a large overpotential for $\mathrm{H}_{2}$ evolution. Since the work functions of the noble metals are larger than that of $\mathrm{TiO}_{2}$ [68-70], a Schottky barrier can be formed at the metal- $\mathrm{TiO}_{2}$ interface, as introduced above. The presence of such barrier can decrease the recombination of photogenerated electron-hole pairs and prolong their lifetime, so greatly enhancing the photocatalytic activity [71]. Among nonnoble metals $\mathrm{NiO}$ was also effective [72-75]. Complex activation procedures are however reported for $\mathrm{NiO}$ cocatalysts, such as combined redox treatments in order to obtain a Ni/NiO system, able to trap electrons while inhibiting the backward electron transfer [76, 77].

The role of metal loading is not univocal. $\mathrm{H}_{2}$ productivity during WS increased with increasing Pt content up to $1 \mathrm{wt} \%$ $[10,78]$. When the metal loading was too high, the $\mathrm{TiO}_{2}$ surface was excessively covered, so decreasing light absorption. Furthermore, excessive metal sites may act as recombination centers. Furthermore, the presence of $\mathrm{O}_{2}$ strongly inhibits hydrogen production due to back reaction to $\mathrm{H}_{2} \mathrm{O}$. In addition, dissolved oxygen can quickly consume electrons of $\mathrm{TiO}_{2}$ due to its stronger ability to trap electrons compared to $\mathrm{H}^{+}$.

$\mathrm{PR}$ reaction mechanism has been proposed for $\mathrm{Pt} / \mathrm{TiO}_{2}$ catalysts (Figure 2) [10]. Alternative reaction paths have been proposed for $\mathrm{Pd} / \mathrm{TiO}_{2}$ catalysts, where the metal is the main responsible for activity, while photoactivation plays a somehow limited role, leading to activated oxygen species on titania, which may contribute to further oxidation of $\mathrm{CO}$, strongly chemisorbed over Pd particles (Figure 3) [79, 80]. However, the true process must be more complex and relies on the determination of intermediates [10]. 


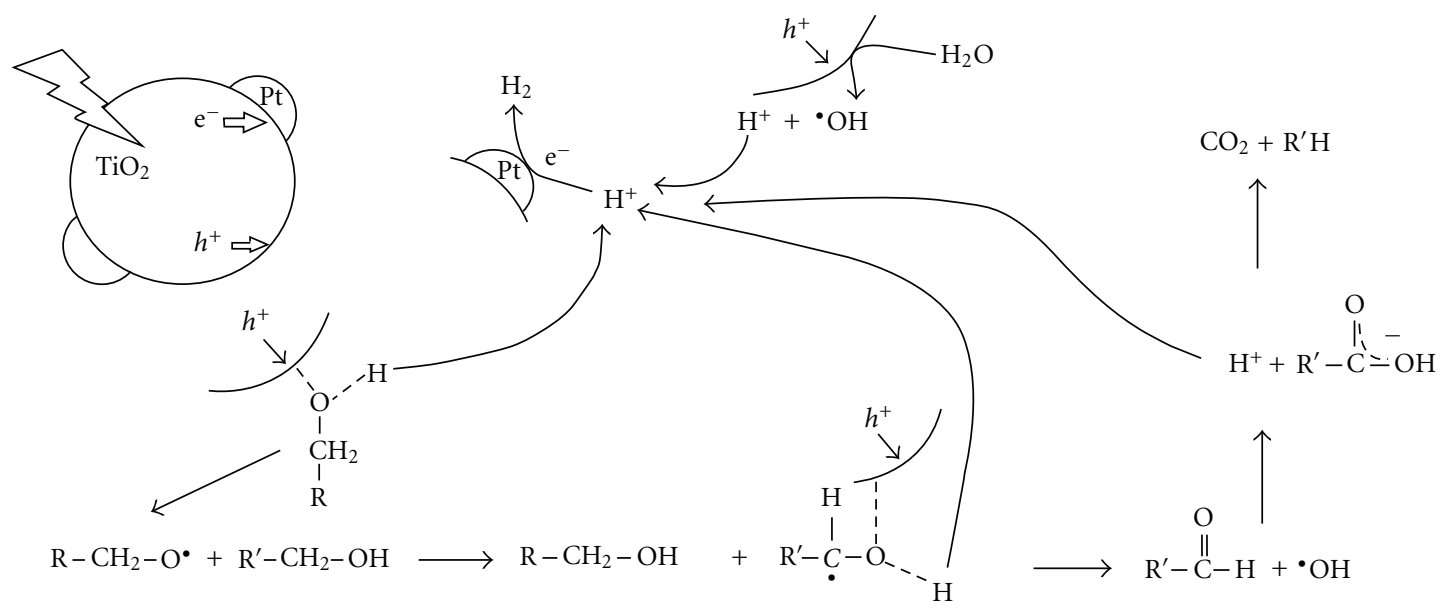

FIgure 2: Proposed alcohols $\mathrm{PR}$ mechanism over $\mathrm{Pt} / \mathrm{TiO}_{2}$ photocatalysts.

One of the key points to develop a reliable catalyst for the PR of biomass derived substrates is its ability to harvest solar light, which is only in part constituted by UV radiation, mostly of IR and visible light (ca. 43\%). Keeping in mind the requirement on minimum bandgap energy and its coupling with the redox potential of the reactants, different strategies have been considered, such as metal and nonmetal ions doping to narrow bandgap energy, dye-sensitization, development of new photocatalysts through bandgap engineering.

Metals have been sometimes added to improve response of the semiconductor (mainly $\mathrm{TiO}_{2}$ and $\mathrm{SrTiO}_{3}$ ) [53, 81-84] under visible light irradiation. Indeed, transition metal ions may add unoccupied orbitals allowing electron transfer with much lower energy absorption than the undoped compound, as confirmed by the theoretical evaluation of density of states [85].

Different transition metals were proposed to improve visible light absorption and to generate effective charge separation $[86,87]$. Doping ions may trap electrons or holes making them available for the reaction but acting as recombination inhibitors, though this point has been not univocally accepted. Attempts to dope $\mathrm{TiO}_{2}$ to improve absorption in the visible region have been also reported [18]. Doping with $\mathrm{V}, \mathrm{Mn}$, and $\mathrm{Cr}$ effectively decreased the $\mathrm{TiO}_{2}$ bandgap energy from 3.2 to $2.2-2.8 \mathrm{eV}$. By contrast, addition of $\mathrm{Au}$ imparted a pink-violet color due to surface plasmon resonance [88]. It has been demonstrated recently that plasmonic nanostructures of noble metals (mainly $\mathrm{Ag}$ and $\mathrm{Au}$ ) induced interesting applications for photocatalysis, in particular for plasmon-enhanced WS on composite photocatalysts containing semiconductor and plasmonic-metal systems [89].

More exotic catalyst formulation $\left(\mathrm{Bi}_{x} \mathrm{Y}_{1-x} \mathrm{VO}_{4}\right)$ showed activity for the PR of glucose under visible light, especially at high Bi loading [90]. Sulphides were also used [1, 91], but they showed much less stability than oxides.

Doping has been proposed with anions, which more likely shift the valence band to higher energy (reducing in any case the bandgap energy) $[53,92]$. Some examples of anions doping led however to very limited red-shift $[14,18]$.
Dye-sensitization, thoroughly explored for solar cells, has some limitations for the present application. In principle a dye, able to absorb visible light, promotes an electron from the highest occupied molecular orbital (HOMO) to the lowest unoccupied one (LUMO) upon photon absorption. The LUMO has higher energy than the conduction band of the semiconductor, so the net effect may be that an electron is pumped in the $\mathrm{CB}$, able to reduce $\mathrm{H}^{+}$to $\mathrm{H}_{2}$ (Figure 4). On the other hand, the situation is complicated by the need of additional redox couples to oxidize water or any other substrate and to recover the original electronic state of the dye molecule (Figure 5). Furthermore, due to their direct participation in the reaction, many concerns are raised by the stability of the dye molecule for repeated reaction cycles.

Finally, the coupling of different semiconductors has been proposed to improve visible light absorption, provided that the band gap energy of one of them is sufficiently small to efficiently harvest solar radiation and that the electron promoted in its conduction band may actually migrate into the conduction band of the other semiconductor [93, 94]. The same concept has been extended to visible light absorbing semiconductors embedded into a lamellar [95] or tubular $[96,97]$ structures, able to withdraw the photogenerated separated charges (Figure 6).

Bioinspired approaches have been also attempted, as recently reviewed [98]. During the photosynthetic process, light is absorbed over a wide range of energy and charge recombination is effectively prevented by electron transfer. In particular, two proteins, called Photosystem I and II, are involved in these key steps, coadjuvated by other enzymes. By looking at the active sites of such natural catalysts, many researchers took inspiration to prepare metal complexes able to carry out some interesting reactions. For instance, the enzyme hydrogenase, responsible of $\mathrm{H}^{+}$reduction to $\mathrm{H}_{2}$, has been immobilized over different materials. $\mathrm{TiO}_{2}$ has been functionalized with both hydrogenase and a Ru-based complex acting as sensitizer. The latter indeed absorbs visible light, transferring one electron into the conduction band of $\mathrm{TiO}_{2}$, which is further transferred to the enzyme for 

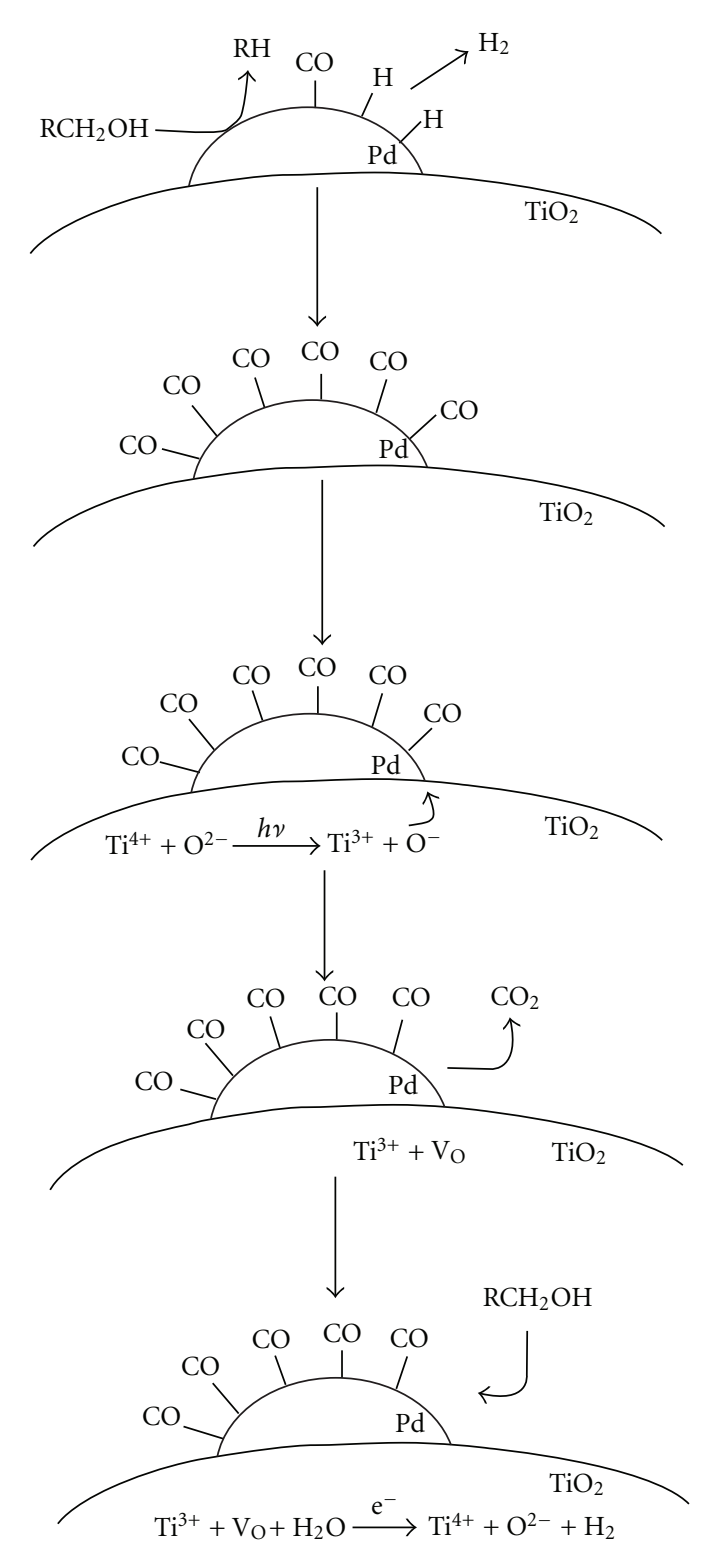

Figure 3: Proposed PR mechanism over $\mathrm{Pd} / \mathrm{TiO}_{2}$ samples. $\mathrm{V}_{\mathrm{O}}$ represents an oxygen vacancy.

$\mathrm{H}_{2}$ production. Of course the cycle should be closed by oxidation of an electron donor species at the $\mathrm{Ru}$ complex side $[99,100]$. Different ligands have been proposed for $\mathrm{Ru}$, the most common ones being polypyridyl or mixed pyridyl$\mathrm{CO}$ complexes. Other metals have been also proposed, such as $\mathrm{Re}, \mathrm{Pt}$, and $\mathrm{Ir}$, showing very high photoactivity for $\mathrm{H}_{2}$ evolution [101-103]. Unfortunately most of these systems did not prove stable under irradiation [104] and leaching of the dye was often observed. Interesting complexes have been also reported for Co, active for both water reduction and oxidation [3].

Unfortunately, for most of the catalytic systems proposed poor attention is paid to deactivation phenomena. Due to mild temperature conditions sintering is usually ruled out,

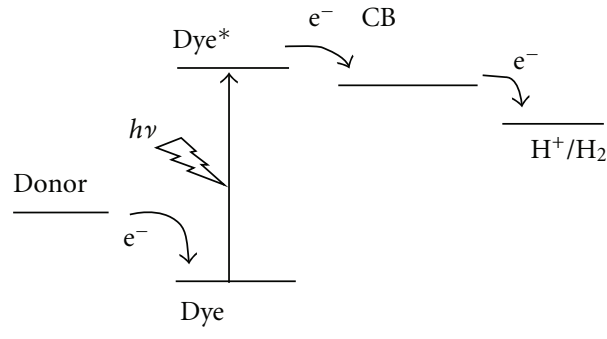

VB

FIGURE 4: Dye-sensitized photocatalytic $\mathrm{H}_{2}$ production.

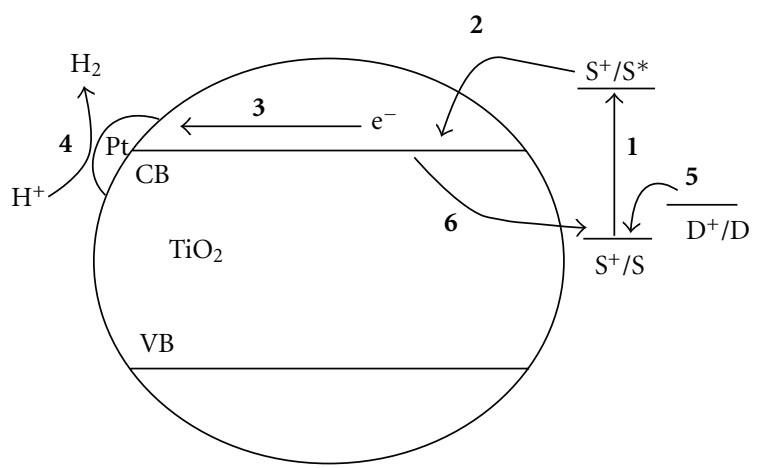

Figure 5: Electron transfer paths in dye-sensitized $\mathrm{TiO}_{2}$. 1: dye (S) excitation; 2: electron injection from the excited dye to $\mathrm{TiO}_{2}$ conduction band (CB); 3: electron entrapment into Pt particles; 4: $\mathrm{H}^{+}$reduction and $\mathrm{H}_{2}$ evolution over the metallic site; 5: regeneration of the oxidized dye by an electron donor (D); 6: electron recombination in the oxidized dye. Readapted from [1].

but poisoning, often by reaction intermediates, and leaching are very critical points [105].

Details on the different catalyst formulations and their features will be discussed in the next sections.

\section{Photoreforming of Alcohols}

A possible mechanism for the PR of alcohols on $\mathrm{TiO}_{2}$ involves the oxidation of water molecules by photoinduced holes in the semiconductor. This produces hydroxyl radicals, which abstract an alpha-hydrogen to create a $\cdot \mathrm{RCH}_{2}-\mathrm{OH}$ radical. The radical is further oxidised to an aldehyde [106108].

The effect of different metals and their loading on the reactivity of titania-based catalysts for the PR of methanol has been investigated [109]. The highest catalytic activity was achieved with Pd and Pt, though significant improvement of the photocatalytic activity has been observed also with Ir and Au. High activity has been ascribed to noble metals due to their hard oxidability, and they are likely involved in the first dehydrogenation step of the reaction. In particular, the metal should be reduced by methanol or in general by the organic substrate [2]. An optimal loading exists for Pd, at ca. $0.5 \mathrm{wt} \%$, and even two optimal loadings (two activity maxima) for Au. This has been correlated to the reaction mechanism, 

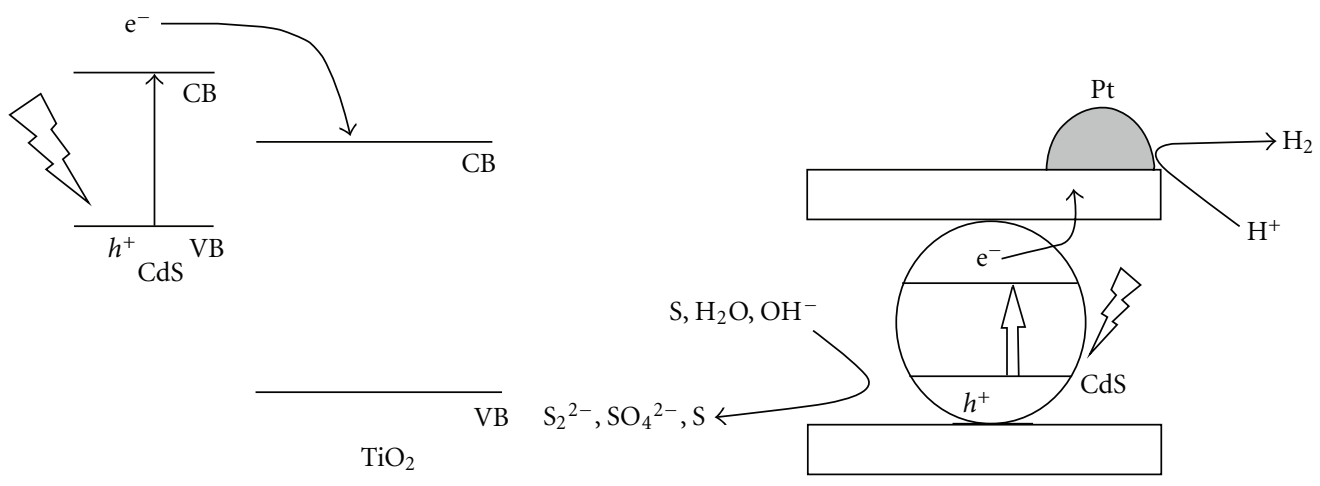

(a)

(b)

FIGURE 6: Mechanism of charge separation in $\mathrm{CdS}-\mathrm{TiO}_{2}$ composite semiconductors (a). Mechanism of photocatalytic $\mathrm{H}_{2}$ evolution on CdS-intercalated layered composites loaded with Pt. Photogenerated electrons in CdS are quickly transferred to host layers through the nanostructure, preventing charge recombination. Readapted from [1].

studied in detail over $\mathrm{Pd} / \mathrm{TiO}_{2}$ catalysts. The metal active sites should be exposed on the surface of the metallic particle, and it should be connected with photoactive sites on titania $[2,109,110]$.

The $\mathrm{H}_{2}$ production rate showed dependent on methanol concentration only for diluted solutions, that is, up to the formation of a monolayer of chemisorbed methanol on the catalyst surface. This suggests that the reaction rate follows a Langmuir-type mechanism. Due to instability of methanol adsorbed over Pd, the authors proposed its decomposition and oxidation to form $\mathrm{CO}$, which is strongly chemisorbed over Pd particles and limits the kinetics of the reaction $[111,112]$. This part of the reaction is suggested to occur also without irradiation, but in the dark Pd poisoning by $\mathrm{CO}$ would stop any further reactive event. Once the catalyst is irradiated with suitable wavelength to promote an electron from the valence band to the conduction band of $\mathrm{TiO}_{2}$, it may form strongly oxidizing species such as $\mathrm{O}^{-}$, which induce further $\mathrm{CO}$ oxidation to $\mathrm{CO}_{2}$, finally released making a metal site free for further methanol adsorption (new reaction cycle). Of course this implies a bifunctional catalyst where the metal active site and the oxidising one on the titania surface are adjacent. In this view, $\mathrm{H}_{2}$ production occurs only when $\mathrm{H}_{2} \mathrm{O}$ reoxidises the reduced titania site (Figure 3). Metals with dehydrogenating activity may form acetaldehyde, which is weakly adsorbed, and it may desorb in gas phase [2].

At least for $\mathrm{TiO}_{2}$, the main oxidising species are reported to be free or trapped holes, $\mathrm{OH}^{\bullet}$ radicals, $\mathrm{O}_{2}{ }^{\bullet-},{ }^{1} \mathrm{O}_{2}, \mathrm{H}_{2} \mathrm{O}_{2}$, and $\mathrm{O}_{2}[30,113]$. In most cases direct oxidation by holes is simply hypothesised, in others the process is reported to be mediated by other highly oxidizing species, for example, $\mathrm{OH}^{\bullet}$ radicals, derived by the reaction of photogenerated holes with water molecules [114]. Several studies highlight the presence of both shallowly and deeply trapped holes on the photocatalyst surface $[115,116]$. Shallowly trapped holes show reactivity and mobility comparable to free ones, reacting thus very rapidly with chemisorbed species. In this case, oxidation processes might even be competitive with ultrafast charge-trapping events. On the other hand, deeply trapped holes, which exhibit lower oxidizing potentials, preferentially react with more mobile physisorbed substances, and the corresponding reaction rates are lower $[105,117]$.

The reaction mechanism of methanol PR over $\mathrm{Au} / \mathrm{TiO}_{2}$ catalysts likely follows a different mechanism [4]. At first, two maxima for reaction rate were observed when varying metal loading up to $5 \mathrm{wt} \%$. Slow rates at low and high loading were interpreted on the same basis above reported for Pd catalysts, that is, unavailable perimeter of metal particles leading to too scarce interphase between the photoactive species $\left(\mathrm{TiO}_{2}\right)$ and the metal. The two maxima are located at 0.5 and $2.0 \mathrm{wt} \% \mathrm{Au}$, likely corresponding, in the view of the authors, to different morphologies of the metal particles. The proposed reaction mechanism is slightly different than that above outlined for Pd. Indeed methanol dissociatively adsorbs on a free metal site forming an adsorbed methoxy species, which seems stable at room temperature. Then, this species is further oxidized by photogeneration of strongly oxidizing agents (e.g., $\mathrm{O}^{-}$) on the surface of titania upon absorption of a photon of sufficient energy $(>3.2 \mathrm{eV})$. The oxidant migrates to the interface of the metal promoting the oxidation of the methoxy group to $\mathrm{CO}_{2}$, which is finally desorbed. This liberates 2 moles of $\mathrm{H}_{2}$ per mol of methanol. Finally, the catalyst is regenerated by water, which acts as an oxidant, refilling titania with its oxygen and making another $\mathrm{H}_{2}$ molecule available (Figure 7). The effect of phase composition and textural properties for $\mathrm{Au} / \mathrm{TiO}_{2}$ catalysts has been also investigated [118].

Similar results for methanol PR over $\mathrm{Au} / \mathrm{TiO}_{2}$ have been reported by Wu et al. [119], particularly focusing on low CO selectivity. The reaction rate was dependent on methanol concentration up to a certain value, after which the reaction order with respect to the reactant was $c a$. zero, and the rate dependence was of Langmuir type. Thus, methanol adsorption on catalyst surface showed a pivotal role. This in turn partly explained the effect of $\mathrm{pH}$, since adsorption (of reactant and intermediates) depends on surface charge of the semiconductor. The role of Au particle size was central most of all to address $\mathrm{CO}$ selectivity problems, since full $\mathrm{CO}$ oxidation may occur at the interface between the metal 

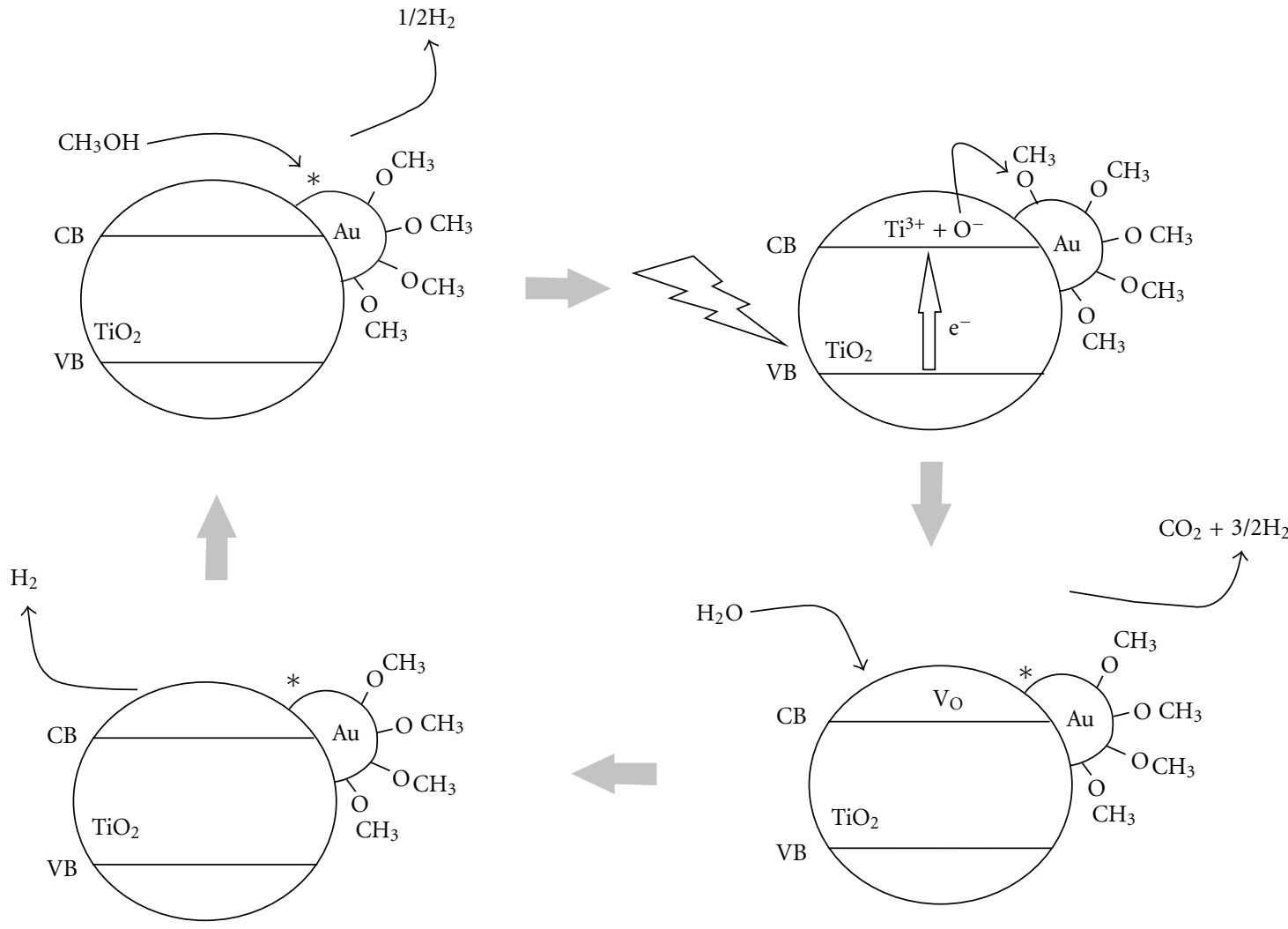

FIgURE 7: Proposed mechanism for methanol PR over $\mathrm{Au} / \mathrm{TiO}_{2}$ catalysts. Readapted from [4].

and the semiconductor. Thus, Au nanoparticles may expose higher contact perimeter for $\mathrm{CO}$ conversion. A parallel investigation on $\mathrm{CO}$ suppression has been carried out over $\mathrm{Pt} / \mathrm{TiO}_{2}$ samples [120]. The effect of Pt loading was considered together with the addition of small amounts of inorganic anions. Focusing on the main route bringing to $\mathrm{CO}$ formation, for example, the dehydrogenation of a formic acid intermediate, $\mathrm{Pt}$ showed to adsorb on defective sites of $\mathrm{TiO}_{2}$, which act both as recombination sites, decreasing photocatalytic efficiency, and as active sites for CO formation. Similarly, anions were competing for adsorption with formic acid.

In this model the rate determining step is the rate of CO removal $[2,80]$. The attribution of the nature of the active oxygen species that removes $\mathrm{CO}_{2}$ from the $\mathrm{Pd}$ surface is still uncertain: $\mathrm{OH}^{*}$ radicals have been observed by electron spin resonance [121]. On the other hand, $\mathrm{H}_{2} \mathrm{O}_{2}$ has been observed over $\mathrm{Pt} / \mathrm{TiO}_{2}$ catalysts, maybe formed through the dimerization of hydroxyl radicals [122].

In this view, a detailed investigation on the effect of Pd loading over titania has been carried out, evidencing the highest reaction rate for methanol PR $0.5 \mathrm{wt} \%$ metal loading [110]. The effect of metal loading has been often interpreted in view of the availability of surface metal sites (increasing with loading) and surface titania exposure, the semiconductor surface being shadowed at too high metal coverage. However, Bowker and coworkers proposed a different explanation, based on the rate determining step of the reaction.
As stated above, the latter should be something happening at the interface between the $\mathrm{Pd}$ particle and $\mathrm{TiO}_{2}$, if the bifunctional mechanism proposed by this research group is valid. Therefore, for reactions with rate dependence on the active sites located at the interphase, the extension of the metal particle perimeter is the predominant factor influencing activity. A calculation of the dependence of the particle perimeter with respect to its volume (radius) is proposed and correlated to initial reaction rate for methanol PR [110]. The model fits the data as for the curve trend with metal loading, though some refinements are needed to provide accurate numerical fitting.

The mechanism of PR of different alcohols has been also investigated on $\mathrm{Pd} / \mathrm{TiO}_{2}$ [79]. The reaction byproducts were widely variable depending on the substrate structure. For instance, methanol gave only $\mathrm{H}_{2}$ and $\mathrm{CO}_{2}$, ethanol and 2-propanol produced also methane as the only major by-product, 1-propanol produced ethane, 1-Butanol and 2-butanol produce propane and ethane, respectively. Dglucose, sucrose and glycerol also showed very good reactivity. The presence of hydrogen atoms in the molecule at the alpha carbon position seems a necessary condition for the reaction. The amount of $\mathrm{H}_{2}$ produced can be estimated by the number of alpha-hydrogen atoms present. In methanol and glycerol reforming all the carbon atoms possess alphahydrogen; thus, complete dehydrogenation occurs on Pd, leaving absorbed $\mathrm{CO}$ on the surface, and converting all the hydrogen atoms into $\mathrm{H}_{2}$ with a rate for glycerol PR $c a$. twice 
than for methanol [13]. As mentioned above [109], the semiconductor plays an active role in the further oxidation of $\mathrm{CO}$ to $\mathrm{CO}_{2}$, thus regenerating an active site. Therefore, $\mathrm{CO}$ actually acts as hole scavenger according to this mechanism [79].

A general rule has been derived to predict the PR products of a general alcohol [80]:

(a) a hydrogen atom in alpha position to the alcoholic function must be present (tertiary alcohols show very poor $\mathrm{H}_{2}$ productivity);

(b) alkyl groups attached to alcohols yield the corresponding alkanes;

(c) methylene groups are fully oxidised to $\mathrm{CO}_{2}$.

$\mathrm{K}_{4} \mathrm{Nb}_{6} \mathrm{O}_{17}$ showed the highest activity for $\mathrm{H}_{2}$ evolution from an aqueous methanol solution, with $\mathrm{ca}$. $50 \%$ quantum yield at $330 \mathrm{~nm}$ [123-125]. The addition of various cocatalysts, such as $\mathrm{NiO}, \mathrm{Au}, \mathrm{Pt}$, and $\mathrm{Cs}$ [126-131] improved $\mathrm{H}_{2}$ productivity even from pure water.

$\mathrm{H}_{2}$ production with only $10 \mathrm{ppm} \mathrm{CO}$ was observed with methanol PR over $\mathrm{Pt}-\mathrm{TiO}_{2}$ catalysts with adsorbed sulfate/ phosphate ions $[120,132]$. Furthermore, a significant $\mathrm{H}_{2}$ production efficiency $(120 \mu \mathrm{mol} / \mathrm{min})$ was obtained with very low methanol concentration without any significant deactivation even after long irradiation time [118].

Ag-doped $\mathrm{TiO}_{2}$ was studied for various applications like sucrose mineralization [133], photocatalytic decomposition of O-cresol [134], degradation of salicylic acid [135], E-coli bacteria degradation [136], and selective $\mathrm{NO}$ reduction to $\mathrm{N}_{2}$ and $\mathrm{N}_{2} \mathrm{O}$ [137]. $\mathrm{Ag}$ and $\mathrm{AgO}$ were differently added to $\mathrm{TiO}_{2}$ for use in the PR of methanol [138]. A broadband around $450-550 \mathrm{~nm}$ was observed corresponding to the surface plasmon resonance of silver particles, and the appearance of this band confirms the presence of metallic silver [139]. The highest $\mathrm{H}_{2}$ productivity was reached with $1 \mathrm{wt} \%$ metal loading and activity increased with substrate concentration up to $5 \%$. At lower concentration mass transfer limitations prevailed, whereas when methanol was too abundant the surface was saturated and the reactions at the interface dominated the whole process [140]. When $\mathrm{Ag}_{2} \mathrm{O} / \mathrm{TiO}_{2}$ and $\mathrm{Ag} / \mathrm{TiO} \mathrm{O}_{2}$ catalysts are irradiated by UV light, titania absorbs the photons and the generated electron-hole pairs are separated by both the metal and the metal oxide. Under solar light the mechanism is different. Silver ions interacting with the surface layers of $\mathrm{TiO}_{2}$ expanding the poor visible response of the latter (bandgap energy $2.88 \mathrm{eV}$ ).

A laser-based method for the PR of methanol over $\mathrm{WO}_{3}$ photocatalyst has been proposed. Hydrogen, carbon monoxide, and methane were obtained and no catalyst aging was observed during 15 days [141]. $\mathrm{NiO}$ was also tested under the same conditions for the PR of methanol and higher alcohols [142]. It is p-type semiconductor with a bandgap energy of $3.5 \mathrm{eV}$ and the potentials of the valence and conduction band edges at +3.0 and $-0.5 \mathrm{~V}$, respectively [143]. Absorption of a photon of suitable energy $\left(E>E_{g}\right)$ causes the transfer of an electron from the valence band of oxygen (2p) to the conduction band of $\mathrm{Ni}(3 \mathrm{~d})$ atom and in turn the reduction of $\mathrm{Ni}^{2+}$ to $\mathrm{Ni}^{+}$. This electron transfer process weakens the Ni-O bond forming an oxygen vacancy. Increasing water concentration with respect to pure methanol allowed to increase the $\mathrm{H}_{2} / \mathrm{CO}$ ratio and to virtually eliminate the byproduct methane.

Copper oxide may also be effective for methanol PR, because the $\mathrm{CuO}$ conduction band is located below that of $\mathrm{TiO}_{2}$, so electron transfer to the conduction band of $\mathrm{CuO}$ is possible [144]. The phenomenon becomes important when a part of incident radiation has wavelength in the UV range. The hole transfer from the valance band of $\mathrm{TiO}_{2}$ to that of $\mathrm{CuO}$ is also possible [145]. Kawai and Sakata [146, 147] have described that the reaction can proceed either stepwise, involving stable intermediates such aldehydes and acids, whereas a single step reaction was proposed by Chen et al. [148]. The overall process can be divided into three steps. At first WS occurs on the surface of $\mathrm{TiO}_{2}$, but its rate is limited by accumulation of holes and oxydryl radicals. In the second step, the photogenerated holes oxidise methanol to formaldehyde, then further oxidized by both $\mathrm{OH}$ radicals and photogenerated holes to produce formic acid. In the third step, formic acid is decarboxylated by the photo-Kolbe reaction to release $\mathrm{CO}_{2} . \mathrm{H}^{+}$ions deprotonated along all the steps transfer to $\mathrm{CuO}$ and reduce to hydrogen by action of the photogenerated electrons [145].

High $\mathrm{CuO} / \mathrm{TiO}_{2}$ activity for methanol PR was reported by Xu and Sun [149]. The active sites for hydrogen generation were likely located at the interface rather than on the isolated $\mathrm{CuO}$ or $\mathrm{TiO}_{2}$ surfaces, since no $\mathrm{H}_{2}$ production was achieved over both the pure oxides. Activity decreased at high $\mathrm{CuO}$ loading, partly for the shrink of available $\mathrm{CuO}$ $\mathrm{TiO}_{2}$ interface and for depressed light absorption by $\mathrm{TiO}_{2}$. Methanol adsorption confirmed a rate limiting step, interpreted according to a Freundlich isotherm. Different causes of catalyst deactivation have been taken into account, with $\mathrm{Cu}$ reduction and leaching (under acidic conditions) as main problems. $\mathrm{Cu}$ doping for $\mathrm{TiO}_{2}$ under visible light irradiation for methanol PR was attempted by Yoong et al. [144].

Sonochemical synthesis of $\mathrm{Pd}, \mathrm{Pt}$, and $\mathrm{Au}$ doped $\mathrm{TiO}_{2}$ photocatalysts was reported for the PR of ethanol [150]. Pt was the most active catalysts due to its higher dispersion. Noble metal doped samples prepared by flame pyrolysis were also proposed for this reaction [151]. The highest $\mathrm{H}_{2}$ yield was achieved for $1 \mathrm{wt} \% \mathrm{Pd} / \mathrm{Pt}-\mathrm{TiO}_{2}$ catalysts, whereas $\mathrm{Rh}$ was too prone to oxidation.

Photodeposition of the cocatalyst is a powerful tool to achieve significantly higher dispersion of the metal phase with respect to impregnation and calcination. Indeed, the latter treatment may induce $\mathrm{TiO}_{2}$ reconstruction over the metallic phase, thus limiting its activity [152].

Flame pyrolysis is a preparation method allowing to obtain single or mixed oxides in nanosized form [153-157]. Titania was also prepared for photocatalytic applications. For instance, Au deposition over titania prepared by flame pyrolysis allowed to improve by $c a$. 30 times the photocatalytic activity for the PR of methanol in liquid phase with respect to the bare titania support and by 50 times with respect to a commercial P25 sample [158]. A gas phase apparatus has been also developed to test the same samples [159]. Methanol 
conversion appeared rather low, and a $\mathrm{CO}_{2} / \mathrm{H}_{2}$ production ratio very much lower than that expected from the stoichiometry was achieved. Some attempts to determine possible byproducts have been made, observing the formation of formaldehyde. However, a reliable quantification of intermediates is very hard with such kind of experimental setting, based on recirculation of the reacting mixture through the starting $20 \mathrm{vol} \% \mathrm{methanol} /$ water solution. Such solution very likely dissolves reaction products (and also $\mathrm{CO}_{2}$ ) much more effectively than pure water, preventing their reliable quantification. Other metals were also tested, obtaining the highest $\mathrm{H}_{2}$ productivity with $1 \mathrm{wt} \% \mathrm{Pt} / \mathrm{TiO}_{2}$ [160].

Gas phase methanol PR was previously proposed by Bowker and coworkers over $\mathrm{Au} / \mathrm{TiO}_{2}$ catalysts. They reported ca. $135 \mu \mathrm{L} / \mathrm{g}_{\text {cat }}$ min $\mathrm{H}_{2}$ productivity, more than three times higher value than in liquid phase photoreforming [161].

The effect of $\mathrm{TiO}_{2}$ crystalline facets exposition on $\mathrm{H}_{2}$ productivity has been taken into account $[39,41,162,163]$. The most stable form of the anatase polymorph is a tetragonal bipyramidal structure in which $\{101\}$ facets are exposed, with a small contribution of $\{001\}$ facets [164], but the use of HF during the synthesis of the semiconductor allows to form truncated bipyramids [165]. Morphological and crystallographic modifications of $\mathrm{TiO}_{2}$ nanocrystals have been achieved by modulating F concentration and dosage [166]. Indeed, the use of $\mathrm{TiF}_{4}$ as precursor, pure or in mixture, allowed the formation of HF in situ. The latter has been used as a shape directing agent, binding selectively to the $\{001\}$ facet of anatase and altering the shape of the resulting nanocrystals. The samples were blue colored, due to free conduction band electrons in $\mathrm{TiO}_{2}$. Additional electrons may come from oxygen vacancies or titanium interstitials. In the latter case, irradation produces conduction band electrons which localize on surface $\mathrm{Ti}$ atoms, but this coloration is quickly quenched upon exposure to oxygen or other oxidizers [167, 168], except under extremely high photon flux [169]. A broad Vis-NIR-IR absorption band has been observed for such samples, commonly attributed to the excitation of conduction band electrons in blue $\mathrm{TiO}_{2}$ and therefore reflecting the density of states of the conduction band [170]. Fluorine in this case is not substitutionally doped into the $\mathrm{TiO}_{2}$ lattice, but it plays an important role in the formation of oxygen vacancies due to stronger $\mathrm{Ti}-\mathrm{F}$ bond with respect to $\mathrm{Ti}-\mathrm{O}$. No hydrogen was evolved in the absence of Pt or photocatalyst or when samples are illuminated with visible light only $(\lambda>430 \mathrm{~nm})$. An induction period of $\sim 1 \mathrm{~h}$ was observed, and $\mathrm{H}_{2}$ productivity up to $\sim 2.1 \mathrm{mmol}$ $\mathrm{H}_{2} \mathrm{~h}^{-1} \mathrm{~g}^{-1}$ was achieved.

Despite the crystal facets exposed, the role of anataserutile junctions was investigated by varying calcination temperature of a Degussa P25 sample, originally starting form a $80: 20$ ratio of the two phases, respectively. Alignment at solid-solid interfaces is one of the most important factors for effective interfacial charge transfer and improved photocatalytic activity. The more numerous the anatase-rutile junctions, the higher the photocatalytic activity for hydrogen production [171]. Indeed, phase boundary suppresses holeelectron recombination and the $\mathrm{CO}$ concentration during PR of methanol, glycerol, and glucose was the lowest. The change of surface acidity/basicity at the interfacial site should be responsible for the suppression of $\mathrm{CO}$ in biomass $\mathrm{PR}$.

Metals, especially noble ones, have been extensively investigated as cocatalysts, in spite of their high cost. A much cheaper alternative has been proposed, using graphite silica, a natural mineral as cocatalyst for $\mathrm{TiO}_{2}$ for the PR of methanol. The physical mixing of the two solids improved the photocatalytic performance with respect to pure $\mathrm{TiO}_{2}$, though a comparison with a typical $\mathrm{Pt} / \mathrm{TiO}_{2}$ formulation revealed $c a$. one eight $\mathrm{H}_{2}$ productivity, only [172]. Therefore, graphite silica was added to a $\mathrm{Pt}+\mathrm{TiO}_{2}$ mixture, obtaining an increase of $\mathrm{H}_{2}$ productivity by $150 \%$. However, when adding the mineral to an impregnated $\mathrm{Pt} / \mathrm{TiO}_{2}$ sample, the $\mathrm{H}_{2}$ yield halved [173].

$\mathrm{SrTiO}_{3}$ has been shown to possess good structural stability as a host for metals [174], and it has been used in photocatalytic WS for hydrogen production with different hole scavengers (alcohols, $\mathrm{Na}_{2} \mathrm{SO}_{3}$, and D-glucose) [175]. The photocatalytic activity was found in the order: $\mathrm{MeOH}>$ EtOH $>$ D-glucose $>2-\mathrm{PrOH}>\mathrm{Na}_{2} \mathrm{SO}_{3}$. Mesoporousassembled $\mathrm{SrTiO}_{3}$ nanocrystals exhibited much higher activity than two commercial photocatalysts, that is, $\mathrm{SrTiO}_{3}$ and $\mathrm{TiO}_{2}$.

Even if the bandgap energy of ETS-10, a large pore zeotype titanosilicate $\left(\mathrm{Na}_{2} \mathrm{TiSi}_{5} \mathrm{O}_{11}\right)$, is higher than that of $\mathrm{TiO}_{2}\left(E_{g}=3.8 \mathrm{eV}\right.$ with respect to $\left.c a .3 .0\right)$, its value was cut to $2.25 \mathrm{eV}$ (visible light absorption) by doping with thiourea. This induced $\mathrm{C}, \mathrm{N}$, and $\mathrm{S}$ ions doping at once, improving the photocatalytic activity for the PR of methanol [176].

The reaction mechanism has been investigated for the PR of ethanol over Pt-based samples. $\mathrm{H}$ atoms belonging to adsorbed hydroxyl groups are reduced by electrons cumulating into $\mathrm{Pt}$ particles at the $\mathrm{Pt}-\mathrm{TiO}_{2}$ interface, while chemisorbed ethoxide species behave as hole traps [151]. Different indications are furnished about the resistance to deactivation during ethanol PR. Indeed on one hand ethanol is one of the easiest substrate to reform, due to its simple structure and limited amount of byproducts. On the other hand poor resistance to deactivation was reported, with heavy deactivation after $20 \mathrm{~h}$ due to the formation of several byproducts, such as acetaldehyde, acetone, and 2-butenal, produced by the partial oxidation and UV decomposition of ethanol $[177,178]$.

$\mathrm{TiO}_{2}$ thin films, functionalized with different metals, were used for ethanol PR [140]. Contrarily to most findings, ethanol showed the most efficient hole scavenger, even better than methanol. The importance of optimizing catalyst exposure in form of films has been highlighted and, interestingly, the quantum yield and the energy conversion efficiency have been provided. A stable photoactive layer based on $\mathrm{TiO}_{2}$ over a porous polymer membrane has been proposed [179]. The PR of ethanol was investigated under UV light irradiation. The influences of $\mathrm{Pt}$ loading, coating, and composition of the $\mathrm{TiO}_{2}$ layer and its aging time were determined. Interestingly, the rate of hydrogen production was higher in the liquid-membrane-gas configuration compared to the liquid-membrane-liquid one, opening the way to effective separation of the gaseous products from the reaction environment. 
In order to decrease significantly catalyst cost $\mathrm{Cu}$-based catalysts were also developed. $\mathrm{Cu}_{x} \mathrm{O}-\mathrm{TiO}_{2}(x=1,2)$ nanocomposites were tested for ethanol PR [180, 181]. The best performance was achieved with $1 \mathrm{wt} \%$ metal loading, due to the main presence of $\mathrm{Cu}(\mathrm{I})$ ions, active sites for the transfer of photogenerated electrons, whereas $\mathrm{Cu}(\mathrm{II})$ species seem to promote electron-hole recombination. Deactivation was also taken into account [149], due to poisoning by accumulation of intermediates and by reduction to the metallic state.

$\mathrm{VO}_{x}$ nanorods were also tested for this application, with a bandgap energy of $2.7 \mathrm{eV}$, with quantum efficiency as high as $40 \%$ without addition of noble metals [182]. Pt-doped $\mathrm{SrTiO}_{3}$ catalysts proved also active under UV and visible light for the PR of methanol and ethanol [175] and mixed La-Ta oxynitrides were proposed as visible-active photocatalysts for hydrogen production from water/ethanol solutions [183].

Ethanol PR occurs through a progressive oxidation coupled with acetal formation, promoted by the presence of surface acidic sites, and accompanied by dehydration and water gas shift reaction [184].

The PR of aqueous solutions of ethanol and glycerol has been performed over $\mathrm{CuO}_{x} / \mathrm{TiO}_{2}$ catalysts prepared in different ways $[181,185]$. The higher dispersion of the metal oxide achieved by embedding $\mathrm{CuO}$ via a microemulsion technique allowed superior activity with respect to classical impregnation. The amount and kind of byproducts depends on the type of catalysts and of substrate. During PR of glycerol some deactivation unfortunately occurred over the most active catalyst, leading to $c a$. $10-20 \%$ loss of activity. Some metal leaching was observed, limited under irradiation, but by far more pronounced under oxidizing and acidic conditions in the absence of light, up to $25 \%$ loss of the cocatalyst.

$\mathrm{CuO}$ was also coated by $\mathrm{RF}$-sputtering over $\mathrm{ZnO}$, trying to improve the performance of a powdered composite [186]. The former material has very low bandgap energy, and it absorbs in the visible region, whereas $\mathrm{ZnO}$ is characterized by much wider bandgap energy. However, the formation of a $\mathrm{p}-\mathrm{n}$ heterojunction favors electron-hole separation. $\mathrm{CuO}$ has been loaded over $\mathrm{ZnO}$ using different RF frequency. The lowest RF-power led to high quality $\mathrm{CuO}-\mathrm{ZnO}$ interfaces (core-shell structure) improving photogenerated charge carrier separation, but completely covering the underlying $\mathrm{ZnO}$ surface. By contrast, the highest RF-power improved $\mathrm{CuO}$ particles dispersion. The most promising performances were obtained for the sample prepared with an intermediate RF-power, leading to a sufficient fraction of uncovered $\mathrm{ZnO}$ available for reactant adsorption and light absorption, together with a higher active area [187]. These samples were successfully used for $\mathrm{H}_{2}$ photogeneration from ethanol/water solutions. However, no complete PR reaction took place, the catalyst mainly produce acetaldehyde through ethanol dehydrogenation, with almost no $\mathrm{CO}_{2}$ formation.

$\mathrm{Au} / \mathrm{TiO}_{2}$ catalysts were tested for the PR of ethanol, particularly focusing on the effect of particle size, varying over one order of magnitude [188]. An investigation of intermediates and products has been carried out by mean of infrared spectroscopy and temperature programmed desorption, evidencing a wide variety of species over the catalyst surface.
The nano-sized catalyst showed higher $\mathrm{H}_{2}$ production, by one order of magnitude, compared with the micro-sized system, but normalizing over the surface area the productivity was equal. This allows to conclude that while nanostructuring the $\mathrm{TiO}_{2}$ semiconductor enhanced productivity, this effect was merely geometrical and did not depend on changes of intrinsic electronic properties.

The reforming of glycerol may lead to the production of 7 moles of $\mathrm{H}_{2}$ per mole of reformed substrate, and it is particularly attractive since glycerol is the major byproduct of biodiesel production. The huge overproduction of glycerol has a negative impact on the global biodiesel economy, since the processes for the economical valorization of glycerol are still limited $[189,190]$. In addition, raw glycerol also contains methanol, water, inorganic salts, free fatty acids, triglycerides, and methyl esters, requiring expensive purification for most applications. Therefore, means for the energetic valorization of this polyalcohol are more than welcome, in light of its increasing availability.

$0.5 \mathrm{wt} \% \mathrm{Pt} / \mathrm{TiO}_{2}$ was tested for glycerol $\mathrm{PR}$ in aqueous solution, increasing the $\mathrm{H}_{2}$ production rate by one order of magnitude with respect to pure water [38]. Other examples of glycerol $\mathrm{PR}$ over $\mathrm{Pd} / \mathrm{TiO}_{2}$ and $\mathrm{Au} / \mathrm{TiO}_{2}$ were proposed in [13], though the catalysts were sensitive to UV light only. Visible light was efficiently harvested by $\mathrm{Fu}$ and $\mathrm{Lu}$ [191], who used heteropolytungstate/ $/ \mathrm{TiO}_{2}$ catalysts. Upon UV irradiation in the presence of an electron donor (glycerol), heteropolytungstate yields dark blue heteropoly blue, absorbing in the visible spectral range. $\mathrm{H}_{2}$ production under visible light was effectively achieved, but a dramatic system deactivation took place, mainly due to the light-induced decomposition of the sensitizer.

Luo et al. [14] proposed Pt-B,N-codoped $\mathrm{TiO}_{2}$ photocatalysts, while $\mathrm{Cu} / \mathrm{TiO}_{2}$ catalysts were active for visible light driven PR of glycerol [192]. High activity for the latter catalytic system was ascribed to very high $\mathrm{Cu}$ dispersion, also achievable by photodeposition $[184,185]$. A significant increase in the absorption at wavelengths shorter than $400 \mathrm{~nm}$ can be assigned to the intrinsic bandgap absorption of $\mathrm{TiO}_{2}$ enhanced by $\mathrm{CuO}$ [193]. High activity can be attributed to the electron transfer from $\mathrm{TiO}_{2}$ to the quantum-sized $\mathrm{CuO}$. The optimal $\mathrm{CuO}$ content in the photocatalyst was found to be $1.3 \mathrm{wt} \%$ with $\mathrm{H}_{2}$ production rate of $2061 \mu \mathrm{mol} \mathrm{h}^{-1} \mathrm{~g}^{-1}, \mathrm{ca} .130$ times the production rate of pure titania, and the apparent QE was $13.4 \%$.

Glycerol PR has been investigated over $\mathrm{Pd} / \mathrm{TiO}_{2}$ and $\mathrm{Au} / \mathrm{TiO}_{2}$ catalysts, achieving $c a$. double $\mathrm{H}_{2}$ production rate with respect to methanol, approximately according to the reactions stoichiometries [13]. Pd, though in lower loading than $\mathrm{Au}$, proved almost twice as active. The reaction mechanism, proposed by Bowker and coworkers for Pd-based photocatalysts is similar to that above outlined for methanol. The adsorbed substrate is decomposed into $\mathrm{CO}$ and $\mathrm{H}_{2}$. $\mathrm{CO}$ is further oxidized to $\mathrm{CO}_{2}$ only under irradiation, thanks to the formation of highly oxidizing species over the titania surface, as already discussed for the mechanism of methanol PR.

Glycerol PR has been also investigated over $\mathrm{Pt} / \mathrm{TiO}_{2}$ catalysts [12]. Glycerol confirmed an efficient scavenger for 
oxidizing species (i.e., holes, hydroxyl radicals, etc.) increasing the rate of hydrogen production with respect to direct water splitting. Very dispersed nanocrystallites of Pt played a determinant role in the photocatalytic process, both as electron scavenger and oxidizing catalyst for dark reaction steps. The effect of noble metal concentration was going through a maximum, as described in other references, in this case for $0.1-0.5 \mathrm{wt} \%$ loading. Also in this case, the reaction rate first increased with the concentration of the photocatalyst and then decreased for high values due to a shielding effect. Neutral or slightly basic conditions improved the reaction rate. This dependence can be due to the favorable positions of the valence- and conduction-band levels of the semiconductor with respect to those of the redox couples in solution, to the charging behavior of the semiconductor surface, to the speciation of the reactants in liquid phase [12, 194, 195]. A slight increase of temperature $\left(60^{\circ} \mathrm{C}\right)$ also proved beneficial to improve reaction rate, likely increasing the rate of the "dark" reaction steps. Many intermediates may also form the most abundant being methanol, which are completely converted to $\mathrm{H}_{2}$ and $\mathrm{CO}_{2}$ after proper reaction time. The kind of oxidizing species was also investigated, particularly focusing on the formation of peroxide species on catalyst surface and in solution [122].

The alcohol may adsorb both in a molecular way or forming alcoxy species, which are more readily oxidized than the $\mathrm{H}$-bonded ones [196, 197]. A correlation between $\mathrm{H}_{2}$ yield and the polarity of alcohols was also proposed over $\mathrm{TiO}_{2}-$ based photocatalysts [151].

Polyols (e.g., glycerol or glucose) showed usually higher activity for photoreforming reactions. Surface $\mathrm{OH}$ sites showed important since they accept photogenerated holes to form hydroxyl radicals $\left({ }^{\bullet} \mathrm{OH}\right)[30,198-200]$, one of the principal reactive oxidant in photocatalytic reactions. They also serve as active sites for the adsorption of reactants and intermediates [201]. It was concluded by time-resolved transient absorption spectroscopy $[202,203]$ that C2-C6 polyols and carbohydrates could scavenge $50-60 \%$ of the photogenerated holes of $\mathrm{TiO}_{2}$ in the time lapse of $6 \mathrm{~ns}$. The scavenging efficiency was higher for increasing the number of $\mathrm{OH}$ groups. The adsorption of polyol on $\mathrm{TiO}_{2}$ can result in levels inside the $\mathrm{TiO}_{2}$ bandgap, responsible for the fast hole trapping efficiency [35]. By comparing isopropanol, propyleneglycol, and glycerol with increasing number of $\mathrm{OH}$ groups in the molecule $\mathrm{H}_{2}$ production increased and alkanes concentration decreased [204]. Furthermore, undercoordinated surface Ti sites can be stabilized by hydroxyl groups, water, or other hydroxylic molecules, such as alcohols, polyols, and carbohydrates $[202,205,206]$. R-OH molecules bind to Ti atoms through their hydroxyl $\mathrm{O}$ and release protons [35]. The conversion of surface Ti to octahedral coordination by the chemisorption of polyols has also been experimentally verified by the observation of Ti K-edge XANES spectra [202]. Two types of adsorption have been observed, however, leading to the same surface intermediate. The role of surface hydroxyls is also of hole scavengers, forming very reactive - $\mathrm{OH}$ radicals which promote substrate oxidation: the higher the number of $\mathrm{OH}$ groups in the molecule, the higher the efficiency of the molecule as hole scavenger. The net effect is the breakup of a $\mathrm{C}-\mathrm{H}$ bond leaving an adsorbed ketyl radical. A detailed reaction mechanism has been proposed for 2-propanol, supported by FT-IR data [207].

\section{Photoreforming of Carbohydrates}

Due to the current low efficiency of the WS process, also biomass derived substrates, such as carbohydrates, are gaining increasing interest as an abundant, renewable, and clean feedstock for hydrogen production. Furthermore, the food industry gives a huge amount of solid and liquid wastes (classified as 2nd generation biomass) which have to be valorized. The sewage from food industry contains first of all water-soluble carbohydrates. Until now the sewage from food industry are purified using mainly biological methods. Using pollutants as electron donors shows the promise for integration of wastes decomposition and $\mathrm{H}_{2}$ production.

The feasibility of $\mathrm{H}_{2}$ photoproduction from carbohydrates, such as sugars, starches, and/or cellulose, on $\mathrm{RuO}_{2}$ / $\mathrm{TiO}_{2} / \mathrm{Pt}$ catalysts was first attested by Kawai and Sakata [11] The abundance of hydroxyls in sugars leads to easier activation of the substrate, though the full degradation of their complex structure is much more complex than simple alcohols. Thus, lower productivity is usually observed. The order of reactivity is consequently starch $<$ sucrose $<$ glucose [10]. The PR of glucose and sucrose over $\mathrm{B}, \mathrm{N}$-codoped $\mathrm{TiO}_{2}$ has been reported even with visible light [14]. A reaction mechanism has been proposed for $\mathrm{Pt} / \mathrm{TiO}_{2}$ [10]. Glucose adsorbs through one of its oxydryls to an under-coordinated Ti(IV) surface site and dissociates leaving a proton and an alkoxide anion. The organic fragment is oxidized by a hole to give a radical, which reacts with another glucose molecule. Further oxidations occur to aldehyde and carboxylic acid derivatives, which are ultimately converted to $\mathrm{CO}_{2}$. Adsorbed $\mathrm{H}^{+}$can be reduced to hydrogen on Pt sites by using photogenerated electrons.

The photocatalytic reforming of aqueous solutions of glucose over metal doped titania has been recently investigated [10]. A possible mechanism for the process has been also proposed, but the details of this complex mechanism still need a firm validation. Indeed, glucose behaves as an efficient hole scavenger for titania, though, the interpretation of the experimental results were insufficiently explained by a significant mechanism due to the lack of structural information [202]. A detailed mechanism for glucose photooxidation on titania has been introduced in [35]. However, only a single adsorption configuration was considered. The adsorption of $\alpha$-D-glucose on the (101) surface of anatase has been computationally investigated [34]. End-on adsorption via a single hydroxyl group, as well as bridge adsorption via two hydroxyl groups, have been considered, in both molecular and dissociative modes. The Ti-O(glucose) bond length showed rather insensitive to the selected hydroxyl group(s) and to the end-on or bridge adsorption mode. By contrast, the bond length decreased significantly when adsorption occurred dissociatively. Ti ions adsorbing glucose in end-on mode showed exposed outward from the surface, while the opposite seems to occur to oxygen ions involved in bridging 
adsorption. Molecular adsorption seems more favorable with respect to dissociative one. The highest occupied electronic state is localized almost completely on the glucose molecule and distinct intragap states appear in several cases; this offers an explanation for the experimentally observed hole trapping in photoexcited titania nanoparticles in the presence of glucose.

The effect of various parameters has been evaluated on the PR of mono-, di-, and poly-saccharides [10]. The rate of $\mathrm{H}_{2}$ evolution decreased with increasing molecular complexity, but microwave pretreatment of soluble starch displayed significantly enhanced $\mathrm{H}_{2}$ evolution. $\mathrm{H}_{2}$ evolution increases with increasing glucose amount, though also water takes part in the reaction. However, the reaction rate is dependent on glucose concentration on the catalyst surface rather than on the solution.

The $\mathrm{H}_{2}$ evolution rate during $\mathrm{PR}$ of glucose increased with $\mathrm{pH}$ with a maximum at $\mathrm{pH}=11$ with a very complex effect. The $\mathrm{pK}_{\mathrm{a}}$ of glucose is about 12.3 [208] and when $\mathrm{pH} \ll \mathrm{pK}_{\mathrm{a}}$, glucose is mainly in its molecular form, preferentially bonding with surface Ti atoms through its hydroxyl [35]. At higher $\mathrm{pH}$, glucose dissociates and the organic anion captures positive holes more efficiently, enhancing activity. If $\mathrm{pH}>\mathrm{pK}_{\mathrm{a}}$, glucose is in the negatively charged form, but $\mathrm{TiO}_{2}$ surface is negatively charged too $(\mathrm{pH}$ higher than the isoelectric point of $\mathrm{TiO}_{2}, c a . \mathrm{pH}=6$ [209]), limiting adsorption and, thus, $\mathrm{H}_{2}$ evolution rate. Furthermore, different $\mathrm{H}_{2}$ production rate was obtained with the two anomers $\alpha$ - and $\beta$-D-glucose. The latter indeed adsorbed in almost planar form over $\mathrm{TiO}_{2}$, leading to lower adsorption [210].

The dependence of the PR activity on glucose concentration showed in line with a Langmuir-type kinetic model and the catalytic activity increased in the order $\mathrm{Ag}, \mathrm{Ru}<\mathrm{Pd}, \mathrm{Au}$, $\mathrm{Rh}<\mathrm{Pt}$ and was correlated with the metal work functions; $\mathrm{Pt}$ shows the highest work function and, thus, it may store more efficiently the photogenerated electrons $[10,105]$.

$\mathrm{NiO}$ was used as cocatalyst for $\mathrm{TiO}_{2}-\mathrm{SiO}_{2}$ during $\mathrm{PR}$ of glucose [211]. An intense absorption onset in the range of 350-400 nm was found for $\mathrm{Ni} / \mathrm{TiO}_{2}-\mathrm{SiO}_{2}$, while the support only absorbed UV-light with wavelength lower than $300 \mathrm{~nm}$. Besides effectively decreasing the bandgap extension, $\mathrm{Ni}$ addition also allowed to limit CO formation with respect to the bare support.

Among alkaline tantalates, $\mathrm{NaTaO}_{3}$ exhibited the highest activity for $\mathrm{H}_{2}$ production from glucose solution, as well as for the water splitting reactions, whereas $\mathrm{LiTaO}_{3}$ showed the lowest activity. This was ascribed to the lower $\mathrm{Ta}-\mathrm{O}-\mathrm{Ta}$ bond angle of $\mathrm{LiTaO}_{3}\left(143^{\circ}\right)$, with respect to $\mathrm{NaTaO}_{3}\left(163^{\circ}\right)$ and $\mathrm{KTaO}_{3}\left(180^{\circ}\right)$. This inhibits the charge migration [212]. Furthermore, the former has wider bandgap energy and poor absorbance [51]. The Fermi level of $\mathrm{NiO}$, used as cocatalyst for such systems is compatible with the energy level of the conduction band of $\mathrm{NaTaO}_{3}$, but not with that of $\mathrm{KTaO}_{3}$.

Hydrogen production was achieved under visible light by $\mathrm{PR}$ of glucose over $\mathrm{Bi}_{x} \mathrm{Y}_{1-x} \mathrm{VO}_{4}$. It was found that a certain amount of $\mathrm{Y}$ doping would promote the transition of $\mathrm{BiVO}_{4}$ from monoclinic to tetragonal phase and finally lead to the formation of tetragonal solid solution. B/Y ratio of $1: 1$ showed the highest activity for hydrogen production.
The rate of $\mathrm{H}_{2}$ production decreased after several hours of reaction, but it was recovered after flushing in $\mathrm{N}_{2}$ [90].

Aqueous sucrose solutions were used as model for sugar industry wastewaters and their $\mathrm{PR}$ reaction was carried out over metal or anion doped $\mathrm{TiO}_{2}$ and $\mathrm{TiO}_{2}-\mathrm{SiO}_{2}$ [18]. The latter semiconductor showed very similar bandgap energy with respect to titania, whereas the addition of metals variously decreased the absorption edge of the photocatalysts. In particular, $1 \% \mathrm{~V} / 5 \% \mathrm{TiO}_{2} / \mathrm{SiO}_{2}$ decreased it to $2.6 \mathrm{eV}$, likely due to the superposition of the $\mathrm{TiO}_{2}$ and $\mathrm{VO}_{x}$ interband absorptions. $1 \% \mathrm{Mn} / 5 \% \mathrm{TiO}_{2} / \mathrm{SiO}_{2}$ and $1 \% \mathrm{Cr} / 5 \%$ $\mathrm{TiO}_{2} / \mathrm{SiO}_{2}$ decreased the $E_{\mathrm{g}}$ to $2.8 \mathrm{eV}$ and $2.2 \mathrm{eV}$, respectively, due to intercalation of doping metals in the $\mathrm{TiO}_{2}$ framework. By contrast, $0.5 \% \mathrm{Au} / 5 \% \mathrm{TiO}_{2} / \mathrm{SiO}_{2}$ exhibited a pink-violet color due to the surface plasmon resonance originating from the collective oscillations of the electrons on the surface of the gold nanoparticles. Visible light is absorbed by gold nanoparticles due to such plasmon resonance, which leads to a photoexcited state of the gold nanoparticles followed by the transfer of the electrons into $\mathrm{TiO}_{2}$ [88]. All the metals strongly improved the photocatalytic activity with respect to the Ti-Si support, with an activity scale $\mathrm{V}>\mathrm{Au}>\mathrm{Mn}>$ Cr. Mn and V ions can trap both electrons and holes [213], whereas $\mathrm{Cr}$ ion can only trap one type of charge carrier [18] so its activity is lower. In addition, vanadium has a larger capability compared to the other metal to coordinate and release oxygen species. On the contrary, anion doping of $\mathrm{TiO}_{2}-\mathrm{SiO}_{2}$ lead to poorer activity, except for sulphur doping.

An increase of $\mathrm{H}_{2}$ production with respect to WS was achieved by Kondarides et al. [38] by PR of a variety of biomass-derived, including monosaccharides, such as pentoses (ribose, arabinose) and hexoses (glucose, galactose, fructose, mannose), alcohols (methanol, ethanol, propanol, butanol), and organic acids (acetic acid, formic acid). In all cases, $\mathrm{H}_{2}$ and $\mathrm{CO}_{2}$ were produced in accordance to the stoichiometry of the general reforming reaction:

$$
\mathrm{C}_{x} \mathrm{H}_{y} \mathrm{O}_{z}+(2 x-z) \mathrm{H}_{2} \mathrm{O} \longrightarrow x \mathrm{CO}_{2}+(2 x-z+y / 2) \mathrm{H}_{2}
$$

The maximum $\mathrm{H}_{2}$ production rate increased almost linearly with the logarithm of the concentration of the substrate, with temperature $\left(60-80^{\circ} \mathrm{C}\right)$ and $\mathrm{pH}$.

\section{Photoreforming of Other Substrates}

5.1. Waste Solutions. A very interesting approach is to combine $\mathrm{H}_{2}$ production and degradation of organic or inorganic pollutants from wastewaters. Various examples have been reported about water solutions containing various alcohols, for example, 2-propanol [214], acids [215, 216], and aldehydes, such as formaldehyde and acetaldehyde [194, 217].

$\mathrm{LaNiO}_{3}$-based catalysts were active under visible light for the PR of formaldehyde [194], while the degradation of azodyes was performed with simultaneous $\mathrm{H}_{2}$ production over Pt- $\mathrm{TiO}_{2}$ [218].

Different examples have been recently reported, such as the treatment of olive mill wastewater over titania, predominantly in the anatase phase, prepared by sol-gel [219]. 
The rate of $\mathrm{H}_{2}$ production decreased with time and with prolonged exposure to light due to deactivation of photocatalyst and decreasing reactant concentration. The suppression of the organic fraction, expressed as Chemical Oxygen Demand (COD) removal was $83 \%$, demonstrating the effectiveness of this approach [220-223]. High $\mathrm{H}_{2}$ productivity was achieved, especially under acidic conditions $(\mathrm{pH}=3)$. The effect of $\mathrm{pH}$ is consistent with the point of zero charge of $\mathrm{TiO}_{2}(\mathrm{pH}=6.8)$, which leads to a positively charged surface in acidic medium. This favors the adsorption of organic pollutants onto the $\mathrm{TiO}_{2}$ surface and facilitates their further degradation [216]. Under these conditions the conduction band position is also favorable to promote the reduction of $\mathrm{H}^{+}$[12]. An optimal catalyst concentration of $c a .2 \mathrm{~g} / \mathrm{L}$ was also observed [219], beyond which turbidity induces light scattering and poor absorption [224].

A variety of possible organic pollutants in wastewaters (alcohols, acids, and aldehydes) have been photoreformed over $\mathrm{Pt} / \mathrm{TiO}_{2}$ under variable reaction conditions, achieving in all cases, except with acetaldehyde, full mineralization according to the reforming reaction above reported. $\mathrm{CO}_{2}$ release in the gas phase was delayed with respect to $\mathrm{H}_{2}$ due to stronger adsorption of $\mathrm{CO}_{2}$ on the photocatalyst surface, to the higher solubility of $\mathrm{CO}_{2}$ in water and/or to mass transfer limitations. It is also likely that the full mineralization of the organic molecule occurs through many consecutive reactions, where the intermediates are slowly oxidized to $\mathrm{CO}_{2}$ while continuously releasing $\mathrm{H}_{2}$ in various reaction steps. The rate of reaction was higher with simpler molecules. The reaction rate confirmed higher under neutral or basic conditions, at relatively high temperature $\left(60-80^{\circ} \mathrm{C}\right)$ [194].

The photocatalytic degradation of azo-dyes, such as Acid Orange 7 , in aerated aqueous $\mathrm{TiO}_{2}$ suspensions has been taken into account [225-227] to achieve full decoloration and the reduction of the chemical oxygen demand of the solution. The reaction was then carried out under anaerobic conditions to explore the possibility of producing hydrogen and to abate dyes such as Acid Orange 7, Basic Blue 41, and Basic Red 46 [218]. Poor photocatalytic activity was achieved with bare $\mathrm{TiO}_{2}$, whereas $\mathrm{H}_{2}$ production increased after addition of $\mathrm{Pt}$, with an apparent activation energy of $8.9 \pm 1.5 \mathrm{kcal} / \mathrm{mol}$, and most of all of dyes, acting as hole scavengers. Decoloration of the solution was observed under UVvis or visible light irradiation, by cleavage of the dye molecule in the vicinity of the azo-bond forming colorless intermediates which may be subsequently oxidized. The amount of $\mathrm{H}_{2}$ additionally produced with respect to WS was proportional to the amount of dye used.

The photocatalytic $\mathrm{H}_{2}$ production has been investigated in the presence of chloroacetic acids over $\mathrm{Pt} / \mathrm{TiO}_{2}$, prepared by photodeposition. Monochloroacetic acid and dichloroacetic acid enhance photocatalytic hydrogen generation, whereas trichloroacetic acid does not. The photocatalytic oxidation of monochloroacetic acid and dichloroacetic acid mainly produces $\mathrm{CO}_{2}, \mathrm{HCl}$, and formaldehyde, whereas the photocatalytic oxidation of trichloroacetic acid mainly produces $\mathrm{CO}_{2}$ and $\mathrm{HCl}$ [228].

Finally, though it is not strictly an example of biomass based waste stream, a process of simultaneous hydrogen production and $\mathrm{H}_{2} \mathrm{~S}$ removal under visible light irradiation has been investigated over bulk CdS decorated with nanoparticles of $\mathrm{TiO}_{2}$ [229].

5.2. Methane Photo-Steam Reforming. The photo-steam reforming of methane $[230,231]$ has been studied only marginally due to limitations in the possible feed compositions at low temperature. Furthermore, gas phase applications for $\mathrm{H}_{2}$ photocatalytic production are much more limited than liquid phase examples. A detailed investigation on methane photo-steam reforming has been proposed by Shimura et al. [232]. Of course the interest would be the application with biogas. $\mathrm{NaTaO}_{3}$ showed the most interesting sample among different tanatalates, though for suitably high $\mathrm{H}_{2}$ productivity different dopants and cocatalysts were used. In particular, La doping, affecting bandgap energy, and $\mathrm{Pt}$ addition, activating methane, were the most effective modifications for $\mathrm{NaTaO}_{3}$. NiO, a good cocatalyst for WS over this catalyst was ineffective for methane photo-steam-reforming. Pt was added by photodeposition, but only a subsequent thermal treatment allowed to reach proper catalyst stability. Some limitations in the $\mathrm{CH}_{4} / \mathrm{H}_{2} \mathrm{O}$ ratio derived both by the need to operate in gas phase and by the formation of adsorbed organic intermediates on catalyst surface rendering it hydrophobic.

\section{Conclusions and Future Perspectives}

The research on materials and methods for the PR of organic substrates has thrown its basis and demonstrated the feasibility of $\mathrm{H}_{2}$ production by this route. From the existing reports it appears that $\mathrm{TiO}_{2}$-based photocatalysts have been extensively investigated and sound reaction mechanism has been proposed for the PR of very simple molecules. Further details however are needed to clarify the basic step of the reaction, surface interactions between the adsorbent and the adsorbate and the nature of active species. The reaction mechanism derived for the photoreforming of methanol has been roughly extended to other substrates, but much heavier efforts are needed to better understand the behavior of complex molecules, such as carbohydrates.

One of the key points is to reach an effective separation of the photogenerated charges. This seems achievable by combining the action of the organic substrate, acting ad hole scavenger, and a metallic phase drawing the photogenerated electrons and acting as active phase for proton reduction. The data reported mostly refer to UV-absorbing materials. Only few reports focus on photocatalysts active under solar light irradiation, which is a pivotal factor to impart practical relevance to this process.

Finally, the research reports on practically relevant substrates, that is, waste solutions, which enable to couple an environmentally relevant problem (waste disposal) with the need to produce clean fuels, are very limited. The potentiality of application of the PR process in this sense is enormous. The advantage is also the possibility to tune the type of waste to the local needs. However, to really exploit this route, it is of primary importance to focus the attention not only to 
the photocatalytic activity of the material, but also to the possible deactivation. Catalyst life represents a key problem when complex (possibly poisoning) substrates are used.

\section{References}

[1] X. Chen, S. Shen, L. Guo, and S. S. Mao, "Semiconductorbased photocatalytic hydrogen generation," Chemical Reviews, vol. 110, no. 11, pp. 6503-6570, 2010.

[2] M. Bowker, "Sustainable hydrogen production by the application of ambient temperature photocatalysis," Green Chemistry, vol. 13, no. 9, pp. 2235-2246, 2011.

[3] V. Artero, M. Chavarot-Kerlidou, and M. Fontecave, "Splitting water with cobalt," Angewandte Chemie-International Edition, vol. 50, no. 32, pp. 7238-7266, 2011.

[4] M. Bowker, L. Millard, J. Greaves, D. James, and J. Soares, "Photocatalysis by Au nanoparticles: reforming of methanol," Gold Bulletin, vol. 37, no. 3-4, pp. 170-173, 2004.

[5] A. Fujishima and K. Honda, "Electrochemical photolysis of water at a semiconductor electrode," Nature, vol. 238, no. 5358, pp. 37-38, 1972.

[6] K. Maeda, K. Teramura, D. Lu et al., "Photocatalyst releasing hydrogen from water," Nature, vol. 440, no. 7082, p. 295, 2006.

[7] S. U. M. Khan, M. Al-Shahry, and W. B. Ingler, "Efficient photochemical water splitting by a chemically modified n$\mathrm{TiO}_{2}$," Science, vol. 297, no. 5590, pp. 2243-2245, 2002.

[8] R. Eisenberg, "Rethinking water splitting," Science, vol. 324, no. 5923, pp. 44-45, 2009.

[9] A. Galińska and J. Walendziewski, "Photocatalytic water splitting over $\mathrm{Pt}-\mathrm{TiO}_{2}$ in the presence of sacrificial reagents," Energy and Fuels, vol. 19, no. 3, pp. 1143-1147, 2005.

[10] X. Fu, J. Long, X. Wang et al., "Photocatalytic reforming of biomass: a systematic study of hydrogen evolution from glucose solution," International Journal of Hydrogen Energy, vol. 33, no. 22, pp. 6484-6491, 2008.

[11] T. Kawai and T. Sakata, "Conversion of carbohydrate into hydrogen fuel by a photocatalytic process," Nature, vol. 286, no. 5772, pp. 474-476, 1980.

[12] V. M. Daskalaki and D. I. Kondarides, "Efficient production of hydrogen by photo-induced reforming of glycerol at ambient conditions," Catalysis Today, vol. 144, no. 1-2, pp. 75-80, 2009.

[13] M. Bowker, P. R. Davies, and L. Saeed Al-Mazroai, "Photocatalytic reforming of glycerol over gold and palladium as an alternative fuel source," Catalysis Letters, vol. 128, no. 3-4, pp. 253-255, 2009.

[14] N. Luo, Z. Jiang, H. Shi, F. Cao, T. Xiao, and P. P. Edwards, "Photo-catalytic conversion of oxygenated hydrocarbons to hydrogen over heteroatom-doped $\mathrm{TiO}_{2}$ catalysts," International Journal of Hydrogen Energy, vol. 34, no. 1, pp. 125-129, 2009.

[15] T. Kida, G. Guan, N. Yamada, T. Ma, K. Kimura, and A. Yoshida, "Hydrogen production from sewage sludge solubilized in hot-compressed water using photocatalyst under light irradiation," International Journal of Hydrogen Energy, vol. 29, no. 3, pp. 269-274, 2004.

[16] N. Taccardi, D. Assenbaum, M. E. M. Berger, A. Bosmann, F. Enzenberger, and R. Wolfel, "Catalytic production of hydrogen from glucose and other carbohydrates under exceptionally mild reaction conditions," Green Chemistry, vol. 12, no. 7, pp. 1150-1156, 2010.
[17] J. C. Colmenares, A. Magdziarz, M. A. Aramendia et al., "Influence of the strong metal support interaction effect (SMSI) of $\mathrm{Pt} / \mathrm{TiO}_{2}$ and $\mathrm{Pd} / \mathrm{TiO}_{2}$ systems in the photocatalytic biohydrogen production from glucose solution," Catalysis Communications, vol. 16, no. 1, pp. 1-6, 2011.

[18] M. Ilie, B. Cojocaru, V. I. Parvulescu, and H. Garcia, "Improving $\mathrm{TiO} 2$ activity in photo-production of hydrogen from sugar industry wastewaters," International Journal of Hydrogen Energy, vol. 36, no. 24, pp. 15509-15518, 2011.

[19] A. Kudo, "Development of photocatalyst materials for water splitting," International Journal of Hydrogen Energy, vol. 31, no. 2, pp. 197-202, 2006.

[20] M. Matsuoka, M. Kitano, M. Takeuchi, K. Tsujimaru, M. Anpo, and J. M. Thomas, "Photocatalysis for new energy production. Recent advances in photocatalytic water splitting reactions for hydrogen production," Catalysis Today, vol. 122, no. 1-2, pp. 51-61, 2007.

[21] K. Maeda and K. Domen, "New non-oxide photocatalysts designed for overall water splitting under visible light," Journal of Physical Chemistry C, vol. 111, no. 22, pp. 78517861, 2007.

[22] F. E. Osterloh, "Inorganic materials as catalysts for photochemical splitting of water," Chemistry of Materials, vol. 20, no. 1, pp. 35-54, 2008.

[23] A. Kudo and Y. Miseki, "Heterogeneous photocatalyst materials for water splitting," Chemical Society Reviews, vol. 38, no. 1, pp. 253-278, 2009.

[24] R. M. N. Yerga, M. Consuelo Álvarez Galván, F. del Valle, J. A. V. de la Mano, and J. L. Fierro, "Water splitting on semiconductor catalysts under visiblelight irradiation," ChemSusChem, vol. 2, no. 6, pp. 471-485, 2009.

[25] M. G. Walter, E. L. Warren, J. R. McKone et al., "Solar water splitting cells," Chemical Reviews, vol. 110, no. 11, pp. 64466473, 2010.

[26] A. L. Linsebigler, G. Lu, and J. T. Yates, "Photocatalysis on $\mathrm{TiO}_{2}$ surfaces: principles, mechanisms, and selected results," Chemical Reviews, vol. 95, no. 3, pp. 735-758, 1995.

[27] M. A. Aramendía, J. C. Colmenares, A. Marinas et al., "Effect of the redox treatment of $\mathrm{Pt} / \mathrm{TiO}_{2}$ system on its photocatalytic behaviour in the gas phase selective photooxidation of propan-2-ol," Catalysis Today, vol. 128, no. 3-4, pp. 235-244, 2007.

[28] M. A. Aramendía, V. Borau, J. C. Colmenares et al., "Modification of the photocatalytic activity of $\mathrm{Pd} / \mathrm{TiO}_{2}$ and $\mathrm{Zn} /$ $\mathrm{TiO}_{2}$ systems through different oxidative and reductive calcination treatments," Applied Catalysis B, vol. 80, no. 1-2, pp. 88-97, 2008.

[29] P. Pichat, J. M. Herrmann, J. Disdier, M. N. Mozzanega, and $\mathrm{H}$. Courbon, "Modification of the $\mathrm{TiO}_{2}$ electron density by ion doping or metal deposit and consequences for photoassisted reactions," Studies in Surface Science and Catalysis, vol. 19, pp. 319-326, 1984.

[30] M. R. Hoffmann, S. T. Martin, W. Choi, and D. W. Bahnemann, "Environmental applications of semiconductor photocatalysis," Chemical Reviews, vol. 95, no. 1, pp. 69-96, 1995.

[31] M. de Oliveira Melo and L. Almeida Silva, "Photocatalytic production of hydrogen: an innovative use for biomass derivatives," The Journal of the Brazilian Chemical Society, vol. 22, no. 8, Article ID 1399, 2011.

[32] S. Chand and S. Bala, "Simulation studies of current transport in metal-insulator-semiconductor Schottky barrier diodes," Physica B, vol. 390, no. 1-2, pp. 179-184, 2007.

[33] G. Wu, T. Chen, G. Zhou, X. Zong, and C. Li, "H-2 pro- 
duction with low $\mathrm{CO}$ selectivity from photocatalytic reforming of glucose on metal/ $\mathrm{TiO}_{2}$ catalysts," Science in China Series B, vol. 51, no. 2, pp. 97-100, 2008.

[34] G. Balducci, "The adsorption of glucose at the surface of anatase: a computational study," Chemical Physics Letters, vol. 494, no. 1-3, pp. 54-59, 2010.

[35] M. Du, J. Feng, and S. B. Zhang, "Photo-oxidation of polyhydroxyl molecules on $\mathrm{TiO}_{2}$ surfaces: from hole scavenging to light-induced self-assembly of $\mathrm{TiO}_{2}$-cyclodextrin wires," Physical Review Letters, vol. 98, no. 6, Article ID 066102, 4 pages, 2007.

[36] D. Barreca, G. Carraro, V. Gombac et al., "Supported metal oxide nanosystems for hydrogen photogeneration: Quo vadis?" Advanced Functional Materials, vol. 21, no. 14, pp. 2611-2623, 2011.

[37] D. Barreca, P. Fornasiero, A. Gasparotto et al., "CVD $\mathrm{Co}_{3} \mathrm{O}_{4}$ nanopyramids: a nano-platform for photo-assisted $\mathrm{H}_{2}$ production," Chemical Vapor Deposition, vol. 16, no. 10 12, pp. 296-300, 2010.

[38] D. I. Kondarides, V. M. Daskalaki, A. Patsoura, and X. E. Verykios, "Hydrogen production by photo-induced reforming of biomass components and derivatives at ambient conditions," Catalysis Letters, vol. 122, no. 1-2, pp. 26-32, 2008.

[39] A. L. Linsebigler, G. Lu, and J. T. Yates Jr., "Photocatalysis on $\mathrm{TiO}_{2}$ surfaces: principles, mechanisms, and selected results," Chemical Reviews, vol. 95, no. 3, pp. 735-758, 1995.

[40] A. Fujishima, X. Zhang, and D. A. Tryk, " $\mathrm{TiO}_{2}$ photocatalysis and related surface phenomena," Surface Science Reports, vol. 63 , no. 12 , pp. 515-582, 2008.

[41] M. A. Henderson, "A surface science perspective on $\mathrm{TiO}_{2}$ photocatalysis," Surface Science Reports, vol. 66, no. 6-7, pp. 185-297, 2011.

[42] L. Spanhel, H. Weller, and A. Henglein, "Photochemistry of semiconductor colloids. 22. Electron injection from illuminated CdS into attached $\mathrm{TiO}_{2}$ and $\mathrm{ZnO}$ particles," Journal of the American Chemical Society, vol. 109, no. 22, pp. 66326635, 1987.

[43] K. E. Karakitsou and X. E. Verykios, "Effects of altervalent cation doping of $\mathrm{TiO}_{2}$ on its performance as a photocatalyst for water cleavage," Journal of Physical Chemistry, vol. 97, no. 6, pp. 1184-1189, 1993.

[44] Y. K. Kho, A. Iwase, W. Y. Teoh, L. Mädler, A. Kudo, and R. Amal, "Photocatalytic $\mathrm{H}_{2}$ evolution over $\mathrm{TiO}_{2}$ nanoparticles. The synergistic effect of anatase and rutile," Journal of Physical Chemistry C, vol. 114, no. 6, pp. 2821-2829, 2010.

[45] J. Shi, J. Chen, Z. Feng et al., "Photoluminescence characteristics of $\mathrm{TiO}_{2}$ and their relationship to the photoassisted reaction of water/methanol mixture," Journal of Physical Chemistry C, vol. 111, no. 2, pp. 693-699, 2007.

[46] J. Jitputti, S. Pavasupree, Y. Suzuki, and S. Yoshikawa, "Synthesis and photocatalytic activity for water-splitting reaction of nanocrystalline mesoporous titania prepared by hydrothermal method," Journal of Solid State Chemistry, vol. 180, no. 5, pp. 1743-1749, 2007.

[47] H. Kato, K. Asakura, and A. Kudo, "Highly efficient water splitting into $\mathrm{H}_{2}$ and $\mathrm{O}_{2}$ over lanthanum-doped $\mathrm{NaTaO}_{3}$ photocatalysts with high crystallinity and surface nanostructure," Journal of the American Chemical Society, vol. 125, no. 10, pp. 3082-3089, 2003.

[48] A. Kudo, H. Kato, and S. Nakagawa, "Water splitting into $\mathrm{H}_{2}$ and $\mathrm{O}_{2}$ on new $\mathrm{Sr}_{2} \mathrm{M}_{2} \mathrm{O}_{7}(\mathrm{M}=\mathrm{Nb}$ and $\mathrm{Ta})$ photocatalysts with layered perovskite structures: factors affecting the photocatalytic activity," Journal of Physical Chemistry B, vol. 104, no. 3, pp. 571-575, 2000.

[49] H. G. Kim, D. W. Hwang, S. W. Bae, J. H. Jung, and J. S. Lee,
"Photocatalytic water splitting over $\mathrm{La}_{2} \mathrm{Ti}_{2} \mathrm{O}_{7}$ synthesized by the polymerizable complex method," Catalysis Letters, vol. 91, no. 3-4, pp. 193-198, 2003.

[50] S. Ikeda, M. Hara, J. N. Kondo et al., "Preparation of $\mathrm{K}_{2} \mathrm{La}_{2} \mathrm{Ti}_{3} \mathrm{O}_{10}$ by polymerized complex method and photocatalytic decomposition of water," Chemistry of Materials, vol. 10, no. 1, pp. 72-77, 1998.

[51] X. Fu, X. Wang, D. Y. C. Leung et al., "Photocatalytic reforming of glucose over La doped alkali tantalate photocatalysts for $\mathrm{H}_{2}$ production," Catalysis Communications, vol. 12, no. 3, pp. 184-187, 2010.

[52] A. Kubacka, M. Fernàndez-García, and G. Colòn, "Advanced nanoarchitectures for solar photocatalytic applications," Chemical Reviews, vol. 112, no. 3, pp. 1555-1614, 2012.

[53] X. Chen and S. S. Mao, "Titanium dioxide nanomaterials: synthesis, properties, modifications, and applications," Chemical Reviews, vol. 107, no. 7, pp. 2891-2959, 2007.

[54] A. Testino, I. R. Bellobono, V. Buscaglia et al., "Optimizing the photocatalytic properties of hydrothermal $\mathrm{TiO}_{2}$ by the control of phase composition and particle morphology. A systematic approach," Journal of the American Chemical Society, vol. 129, no. 12, pp. 3564-3575, 2007.

[55] S. Y. Chae, M. K. Park, S. K. Lee, T. Y. Kim, S. K. Kim, and W. I. Lee, "Preparation of size-controlled $\mathrm{TiO}_{2}$ nanoparticles and derivation of optically transparent photocatalytic films," Chemistry of Materials, vol. 15, no. 17, pp. 3326-3331, 2003.

[56] Z. Zhang, C. C. Wang, R. Zakaria, and J. Y. Ying, "Role of particle size in nanocrystalline TiOi-based photocatalysts," Journal of Physical Chemistry B, vol. 102, no. 52, pp. 1087110878, 1998.

[57] X. Chen, T. Yu, X. Fan et al., "Enhanced activity of mesoporous $\mathrm{Nb}_{2} \mathrm{O}_{5}$ for photocatalytic hydrogen production," Applied Surface Science, vol. 253, no. 20, pp. 8500-8506, 2007.

[58] R. van de Krol, Y. Liang, and J. Schoonman, "Solar hydrogen production with nanostructured metal oxides," Journal of Materials Chemistry, vol. 18, no. 20, pp. 2311-2320, 2008.

[59] N. T. Hahn, H. Ye, D. W. Flaherty, A. J. Bard, and C. B. Mullins, "Reactive ballistic deposition of $\alpha-\mathrm{Fe}_{2} \mathrm{O}_{3}$ thin films for photoelectrochemical water oxidation," ACS Nano, vol. 4, no. 4, pp. 1977-1986, 2010.

[60] V. M. Arakelyan, V. M. Aroutiounian, G. E. Shahnazaryan, and E. A. Khachaturyan, "Thin film n-titanium oxide photoanodes for photoelectrochemical production of hydrogen," Renewable Energy, vol. 33, no. 2, pp. 299-303, 2008.

[61] Y. Li and J. Z. Zhang, "Hydrogen generation from photoelectrochemical water splitting based on nanomaterials," Laser and Photonics Reviews, vol. 4, no. 4, pp. 517-528, 2010.

[62] M. K. I. Senevirathna, P. K. D. D. P. Pitigala, and K. Tennakone, "Water photoreduction with $\mathrm{Cu}_{2} \mathrm{O}$ quantum dots on $\mathrm{TiO}_{2}$ nano-particles," Journal of Photochemistry and Photobiology A, vol. 171, no. 3, pp. 257-259, 2005.

[63] Z. Jiang, F. Yang, N. Luo et al., "Solvothermal synthesis of $\mathrm{N}$-doped $\mathrm{TiO}_{2}$ nanotubes for visible-light-responsive photocatalysis," Chemical Communications, no. 47, pp. 6372-6374, 2008.

[64] S. Palmas, A. M. Polcaro, J. R. Ruiz, A. da Pozzo, M. Mascia, and A. Vacca, " $\mathrm{TiO}_{2}$ photoanodes for electrically enhanced water splitting," International Journal of Hydrogen Energy, vol. 35, no. 13, pp. 6561-6570, 2010.

[65] Y. Li, Y. Hu, S. Peng, G. Lu, and S. Li, "Synthesis of CdS nanorods by an ethylenediamine assisted hydrothermal method for photocatalytic hydrogen evolution," Journal of Physical Chemistry C, vol. 113, no. 21, pp. 9352-9358, 2009. 
[66] Y. Li, T. Sasaki, Y. Shimizu, and N. Koshizaki, "Hexagonalclose-packed, hierarchical amorphous $\mathrm{TiO}_{2}$ nanocolumn arrays: transferability, enhanced photocatalytic activity, and superamphiphilicity without UV irradiation," Journal of the American Chemical Society, vol. 130, no. 44, pp. 1475514762, 2008.

[67] Y. Lin, G. Yuan, R. Liu, S. Zhou, S. W. Sheehan, and D. Wang, "Semiconductor nanostructure-based photoelectrochemical water splitting: a brief review," Chemical Physics Letters, vol. 507, no. 4-6, pp. 209-215, 2011.

[68] H. B. Michaelson, "The work function of the elements and its periodicity," Journal of Applied Physics, vol. 48, no. 11, pp. 4729-4733, 1977.

[69] T. T. Y. Tan, C. K. Yip, D. Beydoun, and R. Amal, "Effects of nano-Ag particles loading on $\mathrm{TiO}_{2}$ photocatalytic reduction of selenate ions," Chemical Engineering Journal, vol. 95, no. 1, pp. 179-186, 2003.

[70] D. E. Eastman, "Photoelectric work functions of transition, rare-earth, and noble metals," Physical Review B, vol. 2, no. 1, pp. 1-2, 1970.

[71] W. X. Dai, X. X. Wang, P. Liu, Y. M. Xu, G. S. Li, and X. Z. Fu, "Effects of electron transfer between $\mathrm{TiO}_{2}$ films and conducting substrates on the photocatalytic oxidation of organic pollutants," Journal of Physical Chemistry B, vol. 110, no. 27, pp. 13470-13476, 2006.

[72] K. Domen, S. Naito, T. Onishi, K. Tamaru, and M. Soma, "Study of the photocatalytic decomposition of water vapor over a NiO-SrTiO ${ }_{3}$ catalyst," Journal of Physical Chemistry, vol. 86, no. 18, pp. 3657-3661, 1982.

[73] B. Zielińska, E. Borowiak-Palen, and R. J. Kalenzuk, "Preparation and characterization of lithium niobate as a novel photocatalyst in hydrogen generation," Journal of Physics and Chemistry of Solids, vol. 69, no. 1, pp. 236-242, 2008.

[74] H. Lin, Y. Chen, and Y. Chen, "Water splitting reaction on $\mathrm{NiO} / \mathrm{InVO}_{4}$ under visible light irradiation," International Journal of Hydrogen Energy, vol. 32, no. 1, pp. 86-92, 2007.

[75] T. Sreethawong, Y. Suzuki, and S. Yoshikawa, "Photocatalytic evolution of hydrogen over mesoporous $\mathrm{TiO}_{2}$ supported $\mathrm{NiO}$ photocatalyst prepared by single-step sol-gel process with surfactant template," International Journal of Hydrogen Energy, vol. 30, no. 10, pp. 1053-1062, 2005.

[76] Y. Miseki, H. Kato, and A. Kudo, "Water splitting into $\mathrm{H}_{2}$ and $\mathrm{O}_{2}$ over $\mathrm{Cs}_{2} \mathrm{Nb}_{4} \mathrm{O}_{11}$ photocatalyst," Chemistry Letters, vol. 34, no. 1, pp. 54-55, 2005.

[77] Z. Zou, J. Ye, K. Sayama, and H. Arakawa, "Direct splitting of water under visible light irradiation with an oxide semiconductor photocatalyst," Nature, vol. 414, no. 6864, pp. 625-627, 2001.

[78] B. Ohtani, K. Iwai, S. I. Nishimoto, and S. Sato, "Role of platinum deposits on titanium(IV) oxide particles: structural and kinetic analyses of photocatalytic reaction in aqueous alcohol and amino acid solutions," Journal of Physical Chemistry B, vol. 101, no. 17, pp. 3349-3359, 1997.

[79] H. Bahruji, M. Bowker, P. R. Davies et al., "Sustainable $\mathrm{H}_{2}$ gas production by photocatalysis," Journal of Photochemistry and Photobiology A, vol. 216, no. 2-4, pp. 115-118, 2010.

[80] H. Bahruji, M. Bowker, P. R. Davies, and F. Pedrono, "New insights into the mechanism of photocatalytic reforming on $\mathrm{Pd} / \mathrm{TiO}_{2}, "$ Applied Catalysis B, vol. 107, no. 1-2, pp. 205-209, 2011.

[81] D. Y. C. Leung, X. L. Fu, C. F. Wang et al., "Hydrogen production over titania-based photocatalysts," ChemSusChem, vol. 3, no. 6, pp. 681-694, 2010.
[82] H. Kato and A. Kudo, "Visible-light-response and photocatalytic activities of $\mathrm{TiO}_{2}$ and $\mathrm{SrTiO}_{3}$ photocatalysts codoped with antimony and chromium," Journal of Physical Chemistry B, vol. 106, no. 19, pp. 5029-5034, 2002.

[83] A. Kudo and M. Sekizawa, "Photocatalytic $\mathrm{H}_{2}$ evolution under visible light irradiation on $\mathrm{Zn}_{1-x} \mathrm{Cu}_{x} \mathrm{~S}$ solid solution," Catalysis Letters, vol. 58, no. 4, pp. 241-243, 1999.

[84] A. Kudo and M. Sekizawa, "Photocatalytic $\mathrm{H}_{2}$ evolution under visible light irradiation on Ni-doped $\mathrm{ZnS}$ photocatalyst," Chemical Communications, no. 15, pp. 1371-1372, 2000.

[85] T. Umebayashi, T. Yamaki, H. Itoh, and K. Asai, "Analysis of electronic structures of 3D transition metal-doped $\mathrm{TiO}_{2}$ based on band calculations," Journal of Physics and Chemistry of Solids, vol. 63, no. 10, pp. 1909-1920, 2002.

[86] S. Rengaraj and X. Z. Li, "Enhanced photocatalytic activity of $\mathrm{TiO}_{2}$ by doping with $\mathrm{Ag}$ for degradation of 2,4,6trichlorophenol in aqueous suspension," Journal of Molecular Catalysis A, vol. 243, no. 1, pp. 60-67, 2006.

[87] M. Anpo and M. Takeuchi, "The design and development of highly reactive titanium oxide photocatalysts operating under visible light irradiation," Journal of Catalysis, vol. 216, no. 1-2, pp. 505-516, 2003.

[88] Y. Tian and T. Tatsuma, "Mechanisms and applications of plasmon-induced charge separation at $\mathrm{TiO}_{2}$ films loaded with gold nanoparticles," Journal of the American Chemical Society, vol. 127, no. 20, pp. 7632-7637, 2005.

[89] S. Linic, P. Christopher, and D. B. Ingram, "Plasmonic-metal nanostructures for efficient conversion of solar to chemical energy," Nature Materials, vol. 10, no. 12, pp. 911-921, 2011.

[90] D. Jing, M. Liu, J. Shi, W. Tang, and L. Guo, "Hydrogen production under visible light by photocatalytic reforming of glucose over an oxide solid solution photocatalyst," Catalysis Communications, vol. 12, no. 4, pp. 264-267, 2010.

[91] R. M. Navarro, M. C. Sanchez-Sanchez, M. C. AlvarezGalvan, F. del Valle, and J. L. G. Fierro, "Hydrogen production from renewable sources: biomass and photocatalytic opportunities," Energy and Environmental Science, vol. 2, no. 1, pp. 35-54, 2009.

[92] K. Maeda, K. Teramura, T. Takata et al., "Overall water splitting on $\left(\mathrm{Ga}_{1-x} \mathrm{Zn}_{x}\right)\left(\mathrm{N}_{1-x} \mathrm{O}_{x}\right)$ solid solution photocatalyst: relationship between physical properties and photocatalytic activity," Journal of Physical Chemistry B, vol. 109, no. 43, pp. 20504-20510, 2005.

[93] K. Shimizu, H. Murayama, A. Nagai, and A. Shimada, "Degradation of hydrophobic organic pollutants by titania pillared fluorine mica as a substrate specific photocatalyst," Applied Catalysis B, vol. 55, no. 2, pp. 141-148, 2005.

[94] S. Liu, J. Yang, and J. Choy, "Microporous $\mathrm{SiO}_{2}-\mathrm{TiO}_{2}$ nanosols pillared montmorillonite for photocatalytic decomposition of methyl orange," Journal of Photochemistry and Photobiology A, vol. 179, no. 1-2, pp. 75-80, 2006.

[95] W. Shangguan, "Hydrogen evolution from water splitting on nanocomposite photocatalysts," Science and Technology of Advanced Materials, vol. 8, no. 1-2, article 76, 2007.

[96] C. Li, J. Yuan, B. Han, L. Jiang, and W. Shangguan, " $\mathrm{TiO}_{2}$ nanotubes incorporated with CdS for photocatalytic hydrogen production from splitting water under visible light irradiation," International Journal of Hydrogen Energy, vol. 35, no. 13, pp. 7073-7079, 2010.

[97] Y. Zhang, Y. Wang, W. Yan, T. Li, S. Li, and Y. R. Hu, "Synthesis of $\mathrm{Cr}_{2} \mathrm{O}_{3}$ /TNTs nanocomposite and its photocatalytic hydrogen generation under visible light irradiation," Applied Surface Science, vol. 255, no. 23, pp. 9508-9511, 2009. 
[98] E. S. Andreiadis, M. Chavarot-Kerlidou, M. Fontecave, and V. Artero, "Artificial photosynthesis: from molecular catalysts for light-driven water splitting to photoelectrochemical cells," Photochemistry and Photobiology, vol. 87, no. 5, pp. 946-964, 2011.

[99] E. Reisner, J. C. Fontecilla-Camps, and F. A. Armstrong, "Catalytic electrochemistry of a [NiFeSe]-hydrogenase on $\mathrm{TiO}_{2}$ and demonstration of its suitability for visible-light driven $\mathrm{H}_{2}$ production," Chemical Communications, no. 5, pp. 550-552, 2009.

[100] E. Reisner, D. J. Powell, C. Cavazza, J. C. FontecillaCamps, and F. A. Armstrong, "Chemoenzymatic synthesis of GD3 oligosaccharides and other disialyl glycans containing natural and non-natural sialic acids," Journal of the American Chemical Society, vol. 131, no. 51, pp. 18467-18477, 2009.

[101] J. I. Goldsmith, W. R. Hudson, M. S. Lowry, T. H. Anderson, and S. Bernhard, "Discovery and high-throughput screening of heteroleptic iridium complexes for photoinduced hydrogen production," Journal of the American Chemical Society, vol. 127, no. 20, pp. 7502-7510, 2005.

[102] P. Zhang, M. Wang, Y. Na, X. Li, Y. Jiang, and L. Sun, "Homogeneous photocatalytic production of hydrogen from water by a bioinspired $\left[\mathrm{Fe}_{2} \mathrm{~S}_{2}\right]$ catalyst with high turnover numbers," Dalton Transactions, vol. 39, no. 5, pp. 1204-1206, 2010.

[103] A. Fihri, V. Artero, A. Pereira, and M. Fontecave, "Efficient $\mathrm{H}_{2}$-producing photocatalytic systems based on cyclometalated iridium- and tricarbonylrhenium-diimine photosensitizers and cobaloxime catalysts," Dalton Transactions, no. 41, pp. 5567-5569, 2008.

[104] W. Gao, J. Sun, T. Akermark et al., "Attachment of a hydrogen-bonding carboxylate side chain to an [FeFe]-hydrogenase model complex: influence on the catalytic mechanism," Chemistry-A European Journal, vol. 16, no. 8, pp. 2537-2546, 2010.

[105] M. Cargnello, A. Gasparotto, V. Gombac, T. Montini, D. Barreca, and P. Fornasiero, "Photocatalytic $\mathrm{H}_{2}$ and addedvalue by-products-the role of metal oxide systems in their synthesis from oxygenates," European Journal of Inorganic Chemistry, vol. 2011, no. 28, pp. 4309-4323, 2011.

[106] L. Sun and J. R. Bolton, "Determination of the quantum yield for the photochemical generation of hydroxyl radicals in $\mathrm{TiO}_{2}$ suspensions," Journal of Physical Chemistry, vol. 100, no. 10, pp. 4127-4134, 1996.

[107] D. Bahnemann, A. Henglein, and L. Spanhel, "Detection of the intermediates of colloidal $\mathrm{TiO}_{2}$-catalysed photoreactions," Faraday Discussions of the Chemical Society, vol. 78, pp. 151-163, 1984.

[108] C. Y. Wang, J. Rabani, D. W. Bahnemann, and J. K. Dohrmann, "Photonic efficiency and quantum yield of formaldehyde formation from methanol in the presence of various $\mathrm{TiO}_{2}$ photocatalysts," Journal of Photochemistry and Photobiology A, vol. 148, no. 1-3, pp. 169-176, 2002.

[109] L. S. Al-Mazroai, M. Bowker, P. Davies et al., "The photocatalytic reforming of methanol," Catalysis Today, vol. 122, no. $1-2$, pp. 46-50, 2007.

[110] M. Bowker, D. James, P. Stone et al., "Catalysis at the metalsupport interface: exemplified by the photocatalytic reforming of methanol on $\mathrm{Pd} / \mathrm{TiO}_{2}$," Journal of Catalysis, vol. 217, no. 2, pp. 427-433, 2003.

[111] R. P. Holroyd and M. Bowker, "Molecular beam studies of alcohol (C1-C3) adsorption and reaction with oxygen precovered Pd(110)," Surface Science, vol. 377-379, pp. 786-790, 1997.
[112] A. Dickinson, D. James, N. Perkins, T. Cassidy, and M. Bowker, "The photocatalytic reforming of methanol," Journal of Molecular Catalysis A, vol. 146, no. 1-2, pp. 211-221, 1999.

[113] A. Fujishima, T. N. Rao, and D. A. Tryk, "Titanium dioxide photocatalysis," Journal of Photochemistry and Photobiology C, vol. 1, no. 1, pp. 1-21, 2000.

[114] J. Marugán, D. Hufschmidt, M. J. López-Muñoz, V. Selzer, and D. Bahnemann, "Photonic efficiency for methanol photooxidation and hydroxyl radical generation on silicasupported $\mathrm{TiO}_{2}$ photocatalysts," Applied Catalysis B, vol. 62, no. 3-4, pp. 201-207, 2006.

[115] D. W. Bahnemann, M. Hilgendorff, and R. Memming, "Charge carrier dynamics at $\mathrm{TiO}_{2}$ particles: reactivity of free and trapped holes," Journal of Physical Chemistry B, vol. 101, no. 21, pp. 4265-4275, 1997.

[116] N. Serpone, D. Lawless, and R. Khairutdinov, "Size effects on the photophysical properties of colloidal anatase $\mathrm{TiO}_{2}$ particles: size quantization or direct transitions in this indirect semiconductor?" Journal of Physical Chemistry, vol. 99, no. 45, pp. 16646-16654, 1995.

[117] Y. Tamaki, A. Furube, M. Murai, K. Hara, R. Katoh, and M. Tachiya, "Direct observation of reactive trapped holes in $\mathrm{TiO}_{2}$ undergoing photocatalytic oxidation of adsorbed alcohols: evaluation of the reaction rates and yields," Journal of the American Chemical Society, vol. 128, no. 2, pp. 416-417, 2006.

[118] O. Rosseler, M. V. Shankar, M. K. L. Du, L. Schmidlin, N. Keller, and V. Keller, "Solar light photocatalytic hydrogen production from water over $\mathrm{Pt}$ and $\mathrm{Au} / \mathrm{TiO}_{2}$ (anatase/rutile) photocatalysts: influence of noble metal and porogen promotion," Journal of Catalysis, vol. 269, no. 1, pp. 179-190, 2010.

[119] G. Wu, T. Chen, W. Su et al., "Conversion of steel mill waste into nanoscale zerovalent iron (nZVI) particles for hydrogen generation via metal-steam reforming," International Journal of Hydrogen Energy, vol. 33, no. 4, pp. 1243-1242, 2008.

[120] G. Wu, T. Chen, X. Zong et al., "Suppressing CO formation by anion adsorption and $\mathrm{Pt}$ deposition on $\mathrm{TiO}_{2}$ in $\mathrm{H}_{2}$ production from photocatalytic reforming of methanol," Journal of Catalysis, vol. 253, no. 1, pp. 225-227, 2008.

[121] A. J. Bard, "Design of semiconductor photoelectrochemical systems for solar energy conversion," Journal of Physical Chemistry, vol. 86, no. 2, pp. 172-177, 1982.

[122] V. M. Daskalaki, P. Panagiotopoulou, and D. I. Kondarides, "Production of peroxide species in $\mathrm{Pt} / \mathrm{TiO}_{2}$ suspensions under conditions of photocatalytic water splitting and glycerol photoreforming," Chemical Engineering Journal, vol. 170, no. 2-3, pp. 433-439, 2011.

[123] K. Domen, A. Kudo, M. Shibata, A. Tanaka, K. I. Maruya, and T. Onishi, "Novel photocatalysts, ion-exchanged $\mathrm{K}_{4} \mathrm{Nb}_{6} \mathrm{O}_{17}$, with a layer structure," Journal of the Chemical Society, Chemical Communications, no. 23, pp. 1706-1707, 1986.

[124] K. Domen, A. Kudo, A. Shinozaki, A. Tanaka, K. I. Maruya, and T. Onishi, "Photodecomposition of water and hydrogen evolution from aqueous methanol solution over novel niobate photocatalysts," Journal of the Chemical Society, Chemical Communications, no. 4, pp. 356-357, 1986.

[125] A. Kudo, A. Tanaka, K. Domen, K. I. Maruya, K. I. Aika, and T. Onishi, "Photocatalytic decomposition of water over $\mathrm{NiOK}_{4} \mathrm{Nb}_{6} \mathrm{O}_{17}$ catalyst," Journal of Catalysis, vol. 111, no. 1, pp. 67-76, 1988.

[126] S. Ikeda, A. Tanaka, K. Shinohara et al., "Effect of the particle size for photocatalytic decomposition of water on Ni-loaded $\mathrm{K}_{4} \mathrm{Nb}_{6} \mathrm{O}_{17}$," Microporous Materials, vol. 9, no. 5-6, pp. 253258, 1997. 
[127] K. Sayama, A. Tanaka, K. Domen, K. Maruya, and T. Onishi, "Improvement of nickel-loaded $\mathrm{K}_{4} \mathrm{Nb}_{6} \mathrm{O}_{17}$ photocatalyst for the decomposition of $\mathrm{H}_{2} \mathrm{O}$," Catalysis Letters, vol. 4, no. 3, pp. 217-222, 1990.

[128] A. Iwase, H. Kato, and A. Kudo, "Nanosized Au particles as an efficient cocatalyst for photocatalytic overall water splitting," Catalysis Letters, vol. 108, no. 1-2, pp. 7-10, 2006.

[129] K. Sayama, A. Tanaka, K. Domen, K. Maruya, and T. Onishi, "Photocatalytic decomposition of water over platinumintercalated $\mathrm{K}_{4} \mathrm{Nb}_{6} \mathrm{O}_{17}$," Journal of Physical Chemistry, vol. 95, no. 3, pp. 1345-1348, 1991.

[130] K. Sayama, K. Yase, H. Arakawa et al., "Photocatalytic activity and reaction mechanism of Pt-intercalated $\mathrm{K}_{4} \mathrm{Nb}_{6} \mathrm{O}_{17}$ catalyst on the water splitting in carbonate salt aqueous solution," Journal of Photochemistry and Photobiology A, vol. 114, no. 2, pp. 125-135, 1998.

[131] K. H. Chung and D. C. Park, "Photocatalytic decomposition of water over cesium-loaded potassium niobate photocatalysts," Journal of Molecular Catalysis A, vol. 129, no. 1, pp. 53-59, 1998.

[132] T. A. Kandiel, R. Dillert, L. Robben, and D. W. Bahnemann, "Photonic efficiency and mechanism of photocatalytic molecular hydrogen production over platinized titanium dioxide from aqueous methanol solutions," Catalysis Today, vol. 161, no. 1, pp. 196-201, 2011.

[133] A. Vamathevan, R. Amal, and D. Beydown, "Photocatalytic oxidation of organics in water using pure and silver-modified titanium dioxide particles," Journal of Photochemistry and Photobiology A, vol. 148, no. 1-3, pp. 233-245, 2002.

[134] Y. L. Kuo, H. W. Chen, and Y. Ku, "Analysis of silver particles incorporated on $\mathrm{TiO}_{2}$ coatings for the photodecomposition of o-cresol," Thin Solid Films, vol. 515, no. 7-8, pp. 34613468, 2007.

[135] W. Lee, H. S. Shen, K. Dwight, and A. Wold, "Effect of silver on the photocatalytic activity of $\mathrm{TiO}_{2}$," Journal of Solid State Chemistry, vol. 106, no. 2, pp. 288-294, 1993.

[136] M. P. Reddy, A. Venugopal, and M. Subrahmanyam, "Hydroxyapatite-supported $\mathrm{Ag}-\mathrm{TiO}_{2}$ as Escherichia coli disinfection photocatalyst," Water Research, vol. 41, no. 2, pp. 379-386, 2007.

[137] K. Shiba, H. Hinode, and M. Wakihara, "Catalytic reduction of nitric monoxide by ethene over $\mathrm{Ag} / \mathrm{TiO}{ }_{2}$ in the presence of excess oxygen," Reaction Kinetics and Catalysis Letters, vol. 64, no. 2, pp. 281-288, 1998.

[138] K. Lalitha, J. K. Reddy, M. V. P. Sharma, V. D. Kumari, and M. Subrahmanyam, "Continuous hydrogen production activity over finely dispersed $\mathrm{Ag}_{2} \mathrm{O} / \mathrm{TiO}_{2}$ catalysts from methanol: water mixtures under solar irradiation: a structure-activity correlation," International Journal of Hydrogen Energy, vol. 35, no. 9, pp. 3991-4001, 2010.

[139] J. Du, J. Zhang, Z. Liu, B. Han, T. Jiang, and Y. Huang, "Controlled synthesis of $\mathrm{Ag} / \mathrm{TiO}_{2}$ core-shell nano wires with smooth and bristled surfaces via a one-step solution route," Langmuir, vol. 22, no. 3, pp. 1307-1312, 2006.

[140] N. Strataki, V. Bekiari, D. I. Kondarides, and P. Liasnos, "Hydrogen production by photocatalytic alcohol reforming employing highly efficient nanocrystalline titania films," Applied Catalysis B, vol. 77, no. 1-2, pp. 184-189, 2007.

[141] M. A. Gondal, A. Hameed, and Z. H. Yamani, "Hydrogen generation by laser transformation of methanol using n-type $\mathrm{WO}_{3}$ semiconductor catalyst," Journal of Molecular Catalysis A, vol. 222, no. 1-2, pp. 259-264, 2004.

[142] A. Hameed and M. A. Gondal, "Production of hydrogen-rich syngas using p-type $\mathrm{NiO}$ catalyst: a laser-based photocatalytic approach," Journal of Molecular Catalysis A, vol. 233, no. 1-2, pp. 35-41, 2005.

[143] F. Di Quarto, C. Sunseri, S. Piazza, and M. C. Romano, "Semiempirical correlation between optical band gap values of oxides and the difference of electronegativity of the elements. Its importance for a quantitative use of photocurrent spectroscopy in corrosion studies," Journal of Physical Chemistry B, vol. 101, no. 14, pp. 2519-2525, 1997.

[144] L. S. Yoong, F. K. Chong, and B. K. Dutta, "Development of copper-doped $\mathrm{TiO}_{2}$ photocatalyst for hydrogen production under visible light," Energy, vol. 34, no. 10, pp. 1652-1661, 2009.

[145] T. Miwa, S. Kaneco, H. Katsumata et al., "Photocatalytic hydrogen production from aqueous methanol solution with $\mathrm{CuO} / \mathrm{Al}_{2} \mathrm{O}_{3} / \mathrm{TiO}_{2}$ nanocomposite," International Journal of Hydrogen Energy, vol. 35, no. 13, pp. 6554-6560, 2010.

[146] T. Kawai and T. Sakata, "Photocatalytic hydrogen production from liquid methanol and water," Chemical Communications, no. 15 , pp. 694-695, 1980.

[147] T. Kawai and T. Sakata, "Photocatalytic hydrogen production from water by the decomposition of poly-vinylchloride, protein, algae dead insects and excrement," Chemistry Letters, vol. 10, no. 1, pp. 81-84, 1981.

[148] J. Chen, D. F. Ollis, W. H. Rulkens, and H. Bruning, "Photocatalyzed oxidation of alcohols and organochlorides in the presence of native $\mathrm{TiO}_{2}$ and metallized $\mathrm{TiO}_{2}$ suspensions. Part (II): photocatalytic mechanisms," Water Research, vol. 33, no. 3, pp. 669-676, 1999.

[149] S. Xu and D. D. Sun, "Significant improvement of photocatalytic hydrogen generation rate over $\mathrm{TiO}_{2}$ with deposited CuO," International Journal of Hydrogen Energy, vol. 34, no. 15, pp. 6096-6104, 2009.

[150] Y. Mizukoshi, Y. Makise, T. Shuto et al., "Immobilization of noble metal nanoparticles on the surface of $\mathrm{TiO}_{2}$ by the sonochemical method: photocatalytic production of hydrogen from an aqueous solution of ethanol," Ultrasonics Sonochemistry, vol. 14, no. 3, pp. 387-392, 2007.

[151] Y. Z. Yang, C. H. Chang, and H. Idriss, "Photo-catalytic production of hydrogen form ethanol over $\mathrm{M} / \mathrm{TiO}_{2}$ catalysts ( $\mathrm{M}=\mathrm{Pd}$, Pt or Rh)," Applied Catalysis B, vol. 67, no. 3-4, pp. 217-222, 2006.

[152] S. Meyer, S. Saborowski, and B. Schäfer, "Photocatalytic reforming of methanol by spatially separated $\mathrm{Pd}$ particles on special $\mathrm{TiO}_{2}$ layers," ChemPhysChem, vol. 7, no. 3, pp. 572574, 2006.

[153] I. Rossetti, L. Fabbrini, N. Ballarini et al., " $\mathrm{V}_{2} \mathrm{O}_{5}-\mathrm{SiO}_{2}$ systems prepared by flame pyrolysis as catalysts for the oxidative dehydrogenation of propane," Journal of Catalysis, vol. 256, no. 1, pp. 45-61, 2008.

[154] I. Rossetti, L. Fabbrini, N. Ballarini et al., "V-Al-O catalysts prepared by flame pyrolysis for the oxidative dehydrogenation of propane to propylene," Catalysis Today, vol. 141, no. 3-4, pp. 271-281, 2009.

[155] L. Mädler and S. E. Pratsinis, "Bismuth oxide nanoparticles by flame spray pyrolysis," Journal of the American Ceramic Society, vol. 85, no. 7, pp. 1713-1718, 2002.

[156] R. Jossen, W. J. Stark, L. Mädler, and S. E. Pratsinis, "Effect of precursor and solvent on particle homogeneity and morphology during spray flame synthesis of nanoparticles," Chemie-Ingenieur-Technik, vol. 75, no. 8, pp. 1129-1130, 2003.

[157] L. Mädler, H. K. Kammler, R. Mueller, and S. E. Pratsinis, "Controlled synthesis of nanostructured particles by flame 
spray pyrolysis," Journal of Aerosol Science, vol. 33, no. 2, pp. 369-389, 2002.

[158] G. L. Chiarello, E. Selli, and L. Forni, "Photocatalytic hydrogen production over flame spray pyrolysis-synthesised $\mathrm{TiO}_{2}$ and $\mathrm{Au} / \mathrm{TiO}_{2}$, " Applied Catalysis B, vol. 84, no. 1-2, pp. 332 339, 2008.

[159] G. L. Chiarello, L. Forni, and E. Selli, "Photocatalytic hydrogen production by liquid- and gas-phase reforming of $\mathrm{CH}_{3} \mathrm{OH}$ over flame-made $\mathrm{TiO}_{2}$ and $\mathrm{Au} / \mathrm{TiO}_{2}$," Catalysis Today, vol. 144, no. 1-2, pp. 69-74, 2009.

[160] G. L. Chiarello, M. H. Aguirre, and E. Selli, "Hydrogen production by photocatalytic steam reforming of methanol on noble metal-modified $\mathrm{TiO}_{2}$," Journal of Catalysis, vol. 273, no. 2, pp. 182-190, 2010.

[161] J. Greaves, L. Al-Mazroai, A. Nuhu, P. Davies, and M. Bowker, "Photocatalytic methanol reforming on $\mathrm{Au} / \mathrm{TiO}_{2}$ for hydrogen production," Gold Bulletin, vol. 39, no. 4, pp. 216-219, 2006.

[162] U. Diebold, "The surface science of titanium dioxide," Surface Science Reports, vol. 48, no. 5-8, pp. 53-229, 2003.

[163] T. L. Thompson and J. T. Yates Jr., "Surface science studies of the photoactivation of $\mathrm{TiO}_{2}$-new photochemical processes," Chemical Reviews, vol. 106, no. 10, pp. 4428-4453, 2006.

[164] M. Lazzeri, A. Vittadini, and A. Selloni, "Structure and energetics of stoichiometric $\mathrm{TiO}_{2}$ anatase surfaces," Physical Review B, vol. 63, no. 15, Article ID 155409, 9 pages, 2001.

[165] H. G. Yang, C. H. Sun, S. Z. Qiao et al., "Anatase $\mathrm{TiO}_{2}$ single crystals with a large percentage of reactive facets," Nature, vol. 453, no. 7195, pp. 638-641, 2008.

[166] T. R. Gordon, M. Cargnello, T. Paik et al., "Nonaqueous synthesis of $\mathrm{TiO}_{2}$ nanocrystals using $\mathrm{TiF}_{4}$ to engineer morphology, oxygen vacancy concentration, and photocatalytic activity," Journal of the American Chemical Society, vol. 134, no. 15, pp. 6751-6761, 2012.

[167] R. F. Howe and M. Gratzel, "EPR observation of trapped electrons in colloidal titanium dioxide," Journal of Physical Chemistry, vol. 89, no. 21, pp. 4495-4499, 1985.

[168] R. F. Howe and M. Gratzel, "EPR study of hydrated anatase under UV irradiation," Journal of Physical Chemistry, vol. 91, no. 14, pp. 3906-3909, 1987.

[169] T. Torimoto, R. J. Fox, and M. A. Fox, "Photoelectrochemical doping of $\mathrm{TiO}_{2}$ particles and the effect of charge carrier density on the photocatalytic activity of microporous semiconductor electrode films," Journal of the Electrochemical Society, vol. 143, no. 11, pp. 3712-3717, 1996.

[170] T. Berger, M. Sterrer, O. Diwald et al., "Light-induced charge separation in anatase $\mathrm{TiO}_{2}$ particles," Journal of Physical Chemistry B, vol. 109, no. 13, pp. 6061-6068, 2005.

[171] Q. Xu, Y. Ma, J. Zhang, X. Wang, Z. Feng, and C. Li, "Enhancing hydrogen production activity and suppressing $\mathrm{CO}$ formation from photocatalytic biomass reforming on $\mathrm{Pt} / \mathrm{TiO}_{2}$ by optimizing anatase-rutile phase structure," Journal of Catalysis, vol. 278, no. 2, pp. 329-335, 2011.

[172] M. Ikeda, Y. Kusumoto, S. Somekawa, P. Ngweniform, and B. Ahmmad, "Effect of graphite silica on $\mathrm{TiO}_{2}$ photocatalysis in hydrogen production from water-methanol solution," Journal of Photochemistry and Photobiology A, vol. 184, no. 3, pp. 306-312, 2006.

[173] M. Ikeda, Y. Kusumoto, Y. Yakushijin, S. Somekawa, P. Ngweniform, and B. Ahmmad, "Hybridized synergy effect among $\mathrm{TiO}_{2}$, Pt and graphite silica on photocatalytic hydrogen production from water-methanol solution," Catalysis Communications, vol. 8, no. 12, pp. 1943-1946, 2007.
[174] T. Ohno, T. Tsubota, Y. Nakamura, and K. Sayama, "Preparation of $\mathrm{S}, \mathrm{C}$ cation-codoped $\mathrm{SrTiO}_{3}$ and its photocatalytic activity under visible light," Applied Catalysis A, vol. 288, no. 1-2, pp. 74-79, 2005.

[175] T. Puangpetch, T. Sreethawong, S. Yoshikawa, and S. Chavadej, "Hydrogen production from photocatalytic water splitting over mesoporous-assembled $\mathrm{SrTiO}_{3}$ nanocrystalbased photocatalysts," Journal of Molecular Catalysis A, vol. 312, no. 1-2, pp. 97-106, 2009.

[176] M. V. Shankar and J. Ye, "Inorganic alkaline-sols as precursors for rapid synthesis of ETS-10 microporous titanosilicates and their photocatalytic reforming of methanol under visible-light irradiation," Catalysis Communications, vol. 11, no. 4, pp. 261-265, 2009.

[177] M. Antoniadou, D. I. Kondarides, and P. Lianos, "Photooxidation products of ethanol during photoelectrochemical operation using a nanocrystalline titania anode and a two compartment chemically biased cell," Catalysis Letters, vol. 129, no. 3-4, pp. 344-349, 2009.

[178] M. Kaneko, J. Nemoto, H. Ueno et al., "Photoelectrochemical reaction of biomass and bio-related compounds with nanoporous $\mathrm{TiO}_{2}$ film photoanode and $\mathrm{O}_{2}$-reducing cathode," Electrochemistry Communications, vol. 8, no. 2, pp. 336340, 2006.

[179] D. E. Tsydenov, V. N. Parmon, and A. V. Vorontsov, “Toward the design of asymmetric photocatalytic membranes for hydrogen production: preparation of $\mathrm{TiO}_{2}$-based membranes and their properties," International Journal of Hydrogen Energy, vol. 37, no. 15, pp. 11046-11060, 2012.

[180] Y. Wu, G. Lu, and $\mathrm{S}$. Li, "The role of $\mathrm{Cu}(\mathrm{I})$ species for photocatalytic hydrogen generation over $\mathrm{CuO}_{x} / \mathrm{TiO}_{2}$," Catalysis Letters, vol. 133, no. 1-2, pp. 97-105, 2009.

[181] D. Barreca, P. Fornasiero, A. Gasparotto et al., "The potential of supported $\mathrm{Cu}_{2} \mathrm{O}$ and $\mathrm{CuO}$ nanosystems in photocatalytic $\mathrm{H}_{2}$ production," ChemSusChem, vol. 2, no. 3, pp. 230-233, 2009.

[182] Y. Wang, Z. Zhang, Y. Zhu et al., "Nanostructured $\mathrm{VO}_{2}$ photocatalysts for hydrogen production," ACS Nano, vol. 2, no. 7, pp. 1492-1496, 2008.

[183] M. Liu, W. You, Z. Lei, T. Takata, K. Domen, and C. Li, "Photocatalytic water splitting to hydrogen over a visible light-driven $\mathrm{LaTaON}_{2}$ catalyst," Chinese Journal of Catalysis, vol. 27, no. 7, pp. 556-558, 2006.

[184] T. Montini, V. Gombac, L. Sordelli et al., "Nanostructured $\mathrm{Cu} / \mathrm{TiO}_{2}$ photocatalysts for $\mathrm{H}_{2}$ production from ethanol and glycerol aqueous solutions," ChemCatChem, vol. 3, no. 3, pp. 574-577, 2011.

[185] V. Gombac, L. Sordelli, T. Montini et al., " $\mathrm{CuO}{ }_{x}-\mathrm{TiO}_{2}$ photocatalysts for $\mathrm{H}_{2}$ production from ethanol and glycerol solutions," Journal of Physical Chemistry A, vol. 114, no. 11, pp. 3916-3925, 2010.

[186] Z. Liu, H. Bai, S. Xu, and D. D. Sun, "Hierarchical CuO/ZnO "corn-like" architecture for photocatalytic hydrogen generation," International Journal of Hydrogen Energy, vol. 36, no. 21, pp. 13473-13480, 2011.

[187] Q. Simon, D. Barreca, A. Gasparotto et al., "Vertically oriented $\mathrm{CuO} / \mathrm{ZnO}$ nanorod arrays: from plasma-assisted synthesis to photocatalytic $\mathrm{H}_{2}$ production," Journal of Materials Chemistry, vol. 22, no. 23, pp. 11739-11747, 2012.

[188] M. A. Nadeem, M. Murdoch, G. I. N. Waterhouse et al., "Photoreaction of ethanol on $\mathrm{Au} / \mathrm{TiO}_{2}$ anatase: comparing the micro to nanoparticle size activities of the support for hydrogen production," Journal of Photochemistry and Photobiology A, vol. 216, no. 2-4, pp. 250-255, 2010. 
[189] M. Aresta, A. Dibenedetto, F. Nocito, and C. Ferragina, "Valorization of bio-glycerol: new catalytic materials for the synthesis of glycerol carbonate via glycerolysis of urea," Journal of Catalysis, vol. 268, no. 1, pp. 106-114, 2009.

[190] A. Behr, J. Eilting, K. Irawadi, J. Leschinski, and F. Lindner, "Improved utilisation of renewable resources: new important derivatives of glycerol," Green Chemistry, vol. 10, no. 1, pp. 13-30, 2008.

[191] N. Fu and G. Lu, "Hydrogen evolution over heteropoly bluesensitized $\mathrm{Pt} / \mathrm{TiO}_{2}$ under visible light irradiation," Catalysis Letters, vol. 127, no. 3-4, pp. 319-322, 2009.

[192] K. Lalitha, G. Sadanandam, V. D. Kumari, M. Subrahmanyam, B. Sreedhar, and N. Y. Hebalkar, "Highly stabilized and finely dispersed $\mathrm{Cu}_{2} \mathrm{O} / \mathrm{TiO}_{2}$ : a promising visible sensitive photocatalyst for continuous production of hydrogen from glycerol:water mixtures," Journal of Physical Chemistry C, vol. 114, no. 50, pp. 22181-22189, 2010.

[193] J. Yu, Y. Hai, and M. Jaroniec, "Photocatalytic hydrogen production over CuO-modified titania," Journal of Colloid and Interface Science, vol. 357, no. 1, pp. 223-228, 2011.

[194] A. Patsoura, D. I. Kondarides, and X. E. Verykios, "Photocatalytic degradation of organic pollutants with simultaneous production of hydrogen," Catalysis Today, vol. 124, no. 3-4, pp. 94-102, 2007.

[195] J. M. Herrmann, "Heterogeneous photocatalysis: state of the art and present applications In honor of Pr. R.L. Burwell Jr. (1912-2003), Former Head of Ipatieff Laboratories, Northwestern University, Evanston (Ill)," Topics in Catalysis, vol. 34, no. 1-4, pp. 49-65, 2005.

[196] S. Pilkenton, S. J. Hwang, and D. Raftery, "Ethanol photocatalysis on $\mathrm{TiO}_{2}$-coated optical microfiber, supported monolayer, and powdered catalysts: an in situ NMR study," Journal of Physical Chemistry B, vol. 103, no. 50, pp. 1115211160, 1999.

[197] W. Xu and D. Raftery, "Photocatalytic oxidation of 2propanol on $\mathrm{TiO}_{2}$ powder and $\mathrm{TiO}_{2}$ monolayer catalysts studied by solid-state NMR," Journal of Physical Chemistry B, vol. 105, no. 19, pp. 4343-4349, 2001.

[198] M. E. Simonsen, Z. Li, and E. G. Søgaard, "Influence of the $\mathrm{OH}$ groups on the photocatalytic activity and photoinduced hydrophilicity of microwave assisted sol-gel $\mathrm{TiO}_{2}$ film," Applied Surface Science, vol. 255, no. 18, pp. 8054-8062, 2009.

[199] O. M. Alfano, M. I. Cabrera, and A. E. Cassano, "Photocatalytic reactions involving hydroxyl radical attack: I. Reaction kinetics formulation with explicit photon absorption effects," Journal of Catalysis, vol. 172, no. 2, pp. 370-379, 1997.

[200] C. S. Turchi and D. F. Ollis, "Photocatalytic degradation of organic water contaminants: mechanisms involving hydroxyl radical attack," Journal of Catalysis, vol. 122, no. 1, pp. 178$192,1990$.

[201] A. H. Boonstra and C. A. H. A. Mutsaers, "Relation between the photoadsorption of oxygen and the number of hydroxyl groups on a titanium dioxide surface," Journal of Physical Chemistry, vol. 79, no. 16, pp. 1694-1698, 1975.

[202] I. A. Shkrob, M. C. Sauer Jr., and D. Gosztola, "Efficient, rapid photooxidation of chemisorbed polyhydroxyl alcohols and carbohydrates by $\mathrm{TiO}_{2}$ nanoparticles in an aqueous solution," Journal of Physical Chemistry B, vol. 108, no. 33, pp. 12512-12517, 2004.

[203] I. A. Shkrob and M. C. Sauer, "Hole scavenging and photostimulated recombination of electron-hole Pairs in aqueous $\mathrm{TiO}_{2}$ nanoparticles," Journal of Physical Chemistry B, vol. 108, no. 33, pp. 12497-12511, 2004.
[204] X. Fu, X. Wang, D. Y. C. Leung, Q. Gu, S. Chen, and H. Huang, "Photocatalytic reforming of C3-polyols for $\mathrm{H}_{2}$ production: part (I). Role of their OH groups," Applied Catalysis B, vol. 106, no. 3-4, pp. 681-688, 2011.

[205] T. Rajh, L. X. Chen, K. Lukas, T. Liu, M. C. Thurnauer, and D. M. Tiede, "Surface restructuring of nanoparticles: an efficient route for ligand-metal oxide crosstalk," Journal of Physical Chemistry B, vol. 106, no. 41, pp. 10543-10552, 2002.

[206] W. Xu, D. Raftery, and J. S. Francisco, "Effect of irradiation sources and oxygen concentration on the photocatalytic oxidation of 2-propanol and acetone studied by in situ FTIR," Journal of Physical Chemistry B, vol. 107, no. 19, pp. 45374544, 2003.

[207] Q. Gu, X. Fu, X. Wang, S. Chen, D. Y. C. Leung, and X. Xie, "Photocatalytic reforming of C3-polyols for $\mathrm{H}_{2}$ production: Part II. FTIR study on the adsorption and photocatalytic reforming reaction of 2-propanol on $\mathrm{Pt} / \mathrm{TiO}_{2}$," Applied Catalysis B, vol. 106, no. 3-4, pp. 689-696, 2011.

[208] C. A. Bunton, G. Savelli, and L. Sepulveda, "Role of glucose and related compounds in micellar and nonmicellar nucleophilic reactions," Journal of Organic Chemistry, vol. 43, no. 10, pp. 1925-1929, 1978.

[209] T. Imae, K. Muto, and S. Ikeda, "The pH dependence of dispersion of $\mathrm{TiO}_{2}$ particles in aqueous surfactant solutions," Colloid \& Polymer Science, vol. 269, no. 1, pp. 43-48, 1991.

[210] M. Zhou, Y. Li, S. Peng, G. Lu, and S. Li, "Effect of epimerization of d-glucose on photocatalytic hydrogen generation over $\mathrm{Pt} / \mathrm{TiO}_{2}$," Catalysis Communications, vol. 18, pp. 21-25, 2012.

[211] R. M. Mohamed and E. S. Aazam, " $\mathrm{H}_{2}$ production with low $\mathrm{CO}$ selectivity from photocatalytic reforming of glucose on $\mathrm{Ni} / \mathrm{TiO}_{2}-\mathrm{SiO}_{2}$," Chinese Journal of Catalysis, vol. 33, no. 2-3, pp. 247-253, 2012.

[212] H. Kato and A. Kudo, "Photocatalytic water splitting into $\mathrm{H}_{2}$ and $\mathrm{O}_{2}$ over various tantalate photocatalysts," Catalysis Today, vol. 78, no. 1-4, pp. 561-569, 2003.

[213] W. Choi, A. Tormin, and M. R. Hoffman, "The role of metal ion dopants in quantum-sized $\mathrm{TiO}_{2}$ : correlation between photoreactivity and charge carrier recombination dynamics," Journal of Physical Chemistry, vol. 98, no. 51, pp. 1366913679, 1994.

[214] B. Zieliñska, E. Borowiak-Palen, and R. J. Kalenczuk, "Photocatalytic hydrogen generation over alkaline-earth titanates in the presence of electron donors," International Journal of Hydrogen Energy, vol. 33, no. 7, pp. 1797-1802, 2008.

[215] S. Shen and L. Guo, "Hydrothermal synthesis, characterization, and photocatalytic performances of $\mathrm{Cr}$ incorporated, and $\mathrm{Cr}$ and $\mathrm{Ti}$ co-incorporated MCM-41 as visible light photocatalysts for water splitting," Catalysis Today, vol. 129, no. 3-4, pp. 414-420, 2007.

[216] X. J. Zheng, L. F. Wei, Z. H. Zhang et al., "Research on photocatalytic $\mathrm{H}_{2}$ production from acetic acid solution by $\mathrm{Pt} / \mathrm{TiO}_{2}$ nanoparticles under UV irradiation," International Journal of Hydrogen Energy, vol. 34, no. 22, pp. 9033-9041, 2009.

[217] L. Jia, J. Li, and W. Fang, "Effect of $\mathrm{H}_{2} / \mathrm{CO}_{2}$ mixture gas treatment temperature on the activity of $\mathrm{LaNiO}_{3}$ catalyst for hydrogen production from formaldehyde aqueous solution under visible light," Journal of Alloys and Compounds, vol. 489, no. 2, pp. L13-L16, 2010.

[218] A. Patsoura, D. I. Kondarides, and X. E. Verykios, "Enhancement of photoinduced hydrogen production from irradiated $\mathrm{Pt} / \mathrm{TiO}_{2}$ suspensions with simultaneous degradation of azodyes," Applied Catalysis B, vol. 64, no. 3-4, pp. 171-179, 2006. 
[219] M. I. Badawy, M. Y. Ghaly, and M. E. M. Ali, "Photocatalytic hydrogen production over nanostructured mesoporous titania from olive mill wastewater," Desalination, vol. 267, no. 23, pp. 250-255, 2011.

[220] K. Mogyorosi, I. Dekany, and H. J. Fendler, "Preparation and characterization of clay mineral intercalated titanium dioxide nanoparticles," Langmuir, vol. 19, no. 7, pp. 2938-2946, 2003.

[221] A. Scalfani, L. Palmisano, and M. Schiavello, "Influence of the preparation methods of titanium dioxide on the photocatalytic degradation of phenol in aqueous dispersion," Journal of Physical Chemistry, vol. 94, no. 2, pp. 829-832, 1990.

[222] M. Andersson, L. Österlund, S. Ljungstrom, and A. Palmqvist, "Preparation of nanosize anatase and rutile $\mathrm{TiO}_{2}$ by hydrothermal treatment of microemulsions and their activity for photocatalytic wet oxidation of phenol," Journal of Physical Chemistry B, vol. 106, no. 41, pp. 10674-10679, 2002.

[223] M. Addamo, V. Augugliaro, A. di Paola et al., "Preparation, characterization, and photoactivity of polycrystalline nanostructured $\mathrm{TiO}_{2}$ catalysts," Journal of Physical Chemistry B, vol. 108, no. 10, pp. 3303-3310, 2004.

[224] C. C. Chen, C. S. Lu, Y. C. Chung, and J. L. Jan, "UV light induced photodegradation of malachite green on $\mathrm{TiO}_{2}$ nanoparticles," Journal of Hazardous Materials, vol. 141, no. 3, pp. 520-528, 2007.

[225] F. Kiriakidou, D. I. Kondarides, and X. E. Verykios, "The effect of operational parameters and $\mathrm{TiO}_{2}$-doping on the photocatalytic degradation of azo-dyes," Catalysis Today, vol. 54, no. 1, pp. 119-130, 1999.

[226] M. Stylidi, D. I. Kondarides, and X. E. Verykios, "Pathways of solar light-induced photocatalytic degradation of azo dyes in aqueous $\mathrm{TiO}_{2}$ suspensions," Applied Catalysis B, vol. 40, no. 4, pp. 271-286, 2003.

[227] M. Stylidi, D. I. Kondarides, and X. E. Verykios, "Visible light-induced photocatalytic degradation of acid orange 7 in aqueous $\mathrm{TiO}_{2}$ suspensions," Applied Catalysis B, vol. 47, no. 3, pp. 189-201, 2004.

[228] Y. Li, Y. Xie, S. Peng, G. Lu, and S. Li, "Photocatalytic hydrogen generation in the presence of chloroacetic acids over Pt/TiO ${ }_{2}$," Chemosphere, vol. 63, no. 8, pp. 1312-1318, 2006.

[229] J. S. Jang, H. G. Kim, H. G. Kim, and J. S. Lee, "Simultaneous hydrogen production and decomposition of $\mathrm{H}_{2} \mathrm{~S}$ dissolved in alkaline water over $\mathrm{CdS}-\mathrm{TiO}_{2}$ composite photocatalysts under visible light irradiation," International Journal of Hydrogen Energy, vol. 32, no. 18, pp. 4786-4791, 2007.

[230] H. Yoshida, S. Kato, K. Hirao, J. I. Nishimoto, and T. Hattori, "Photocatalytic steam reforming of methane over platinumloaded semiconductors for hydrogen production," Chemistry Letters, vol. 36, no. 3, pp. 430-431, 2007.

[231] H. Yoshida, K. Hirao, J. I. Nishimoto et al., "Hydrogen production from methane and water on platinum loaded titanium oxide photocatalysts," Journal of Physical Chemistry C, vol. 112, no. 14, pp. 5542-5551, 2008.

[232] K. Shimura, S. Kato, T. Yoshida, H. Itoh, T. Hattori, and H. Yoshida, "Photocatalytic steam reforming of methane over sodium tantalate," Journal of Physical Chemistry C, vol. 114, no. 8, pp. 3493-3503, 2010. 

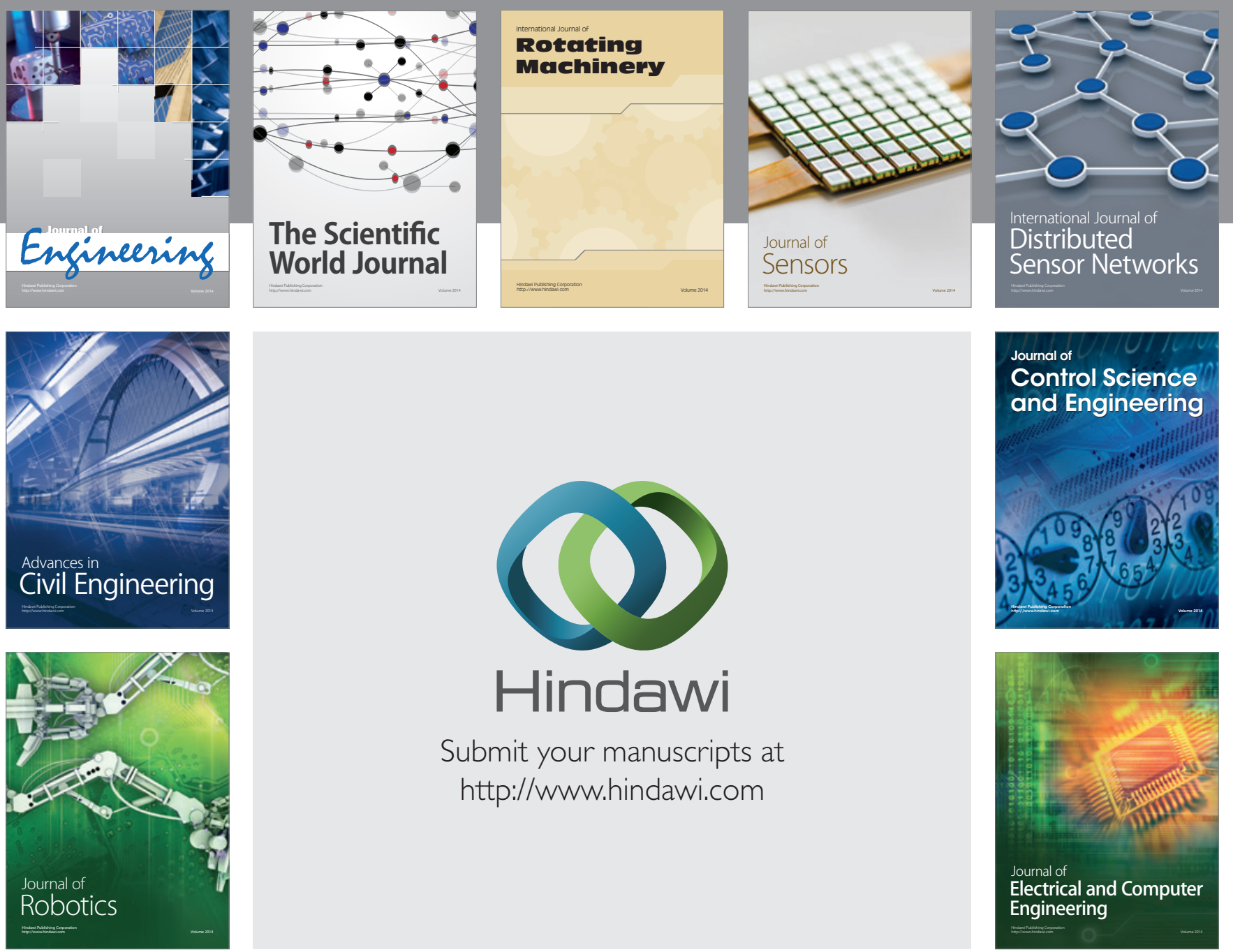

Submit your manuscripts at

http://www.hindawi.com
